Canadian

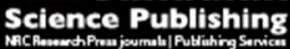

Canadian Geotechnical Journal Revue canadienne de géotechnique

\title{
Design of ballasted railway track foundations using numerical modelling Part I: Development
}

\begin{tabular}{|r|l|}
\hline Journal: & Canadian Geotechnical Journal \\
\hline Manuscript ID & cgj-2016-0633.R1 \\
\hline Manuscript Type: & Article \\
\hline Date Submitted by the Author: & 18 -Apr-2017 \\
\hline Complete List of Authors: & $\begin{array}{l}\text { Sayeed, Md. Abu; Curtin University, Civil Engineering } \\
\text { Shahin, Mohamed; Curtin University, Civil Engineering }\end{array}$ \\
\hline Keyword: & $\begin{array}{l}\text { Finite elements, numerical modelling, ballasted railway track foundations, } \\
\text { subgrade progressive shear failure, track excessive plastic deformation }\end{array}$ \\
\hline & \multicolumn{2}{|l}{} \\
\hline
\end{tabular}

SCHOLARONE ${ }^{m}$

Manuscripts 


\title{
Design of ballasted railway track foundations using numerical modelling Part I: Development
}

\author{
Md. Abu Sayeed \\ PhD Candidate, Department of Civil Engineering, \\ Curtin University, WA 6845, Australia \\ Mobile: +61404214238 \\ E-mail: sayeed.ce00@yahoo.com
}

\begin{abstract}
Mohamed A. Shahin*
Associate Professor, Department of Civil Engineering, Curtin University, WA 6845, Australia

Phone: +61-8-9266 1822; Fax: +61-8-9266 2681

E-mail: M.Shahin@curtin.edu.au
\end{abstract}

*Corresponding author

SUBMITTED TO: CANADIAN GEOTECHNICAL JOURNAL 


\title{
Design of ballasted railway track foundations using numerical modelling
}

\section{Part I: Development}

\begin{abstract}
In this paper, a new design method for ballasted railway track foundations is developed, which can sustain high speed trains and heavy axle loads. The proposed method is intended to prevent two most common track failures, namely the progressive shear failure of track subgrade and excessive plastic deformation of track substructure (i.e., ballast + subgrade). The method is based on improved empirical models and sophisticated three dimensional (3D) finite elements (FE) numerical analyses. The improved empirical models are used for predicting the cumulative plastic deformation of the track, whereas the stress parameters of the ballast and subgrade layers are obtained from the 3D FE numerical analyses. The outcomes are then synthesized into a set of design charts that formed the core of the proposed design method so that it can be readily used by railway geotechnical engineers for routine design practice. The design method can be applied to various practical conditions of train-track-ground systems, including the modulus, thickness and type of ballast and subgrade. In addition, the traffic parameters which have a significant influence on track performance are also considered in the design method, including the wheel spacing, train speed, and traffic tonnage. The new design method has significant advantages over the existing methods and offers a major role in modern railway tack design and code of practice. The applications of the new design method are presented and explained in a companion paper (i.e., Part II: Applications).
\end{abstract}

Keywords: Finite elements, numerical modelling, ballasted railway track foundations, subgrade progressive shear failure, track excessive plastic deformation. 


\section{Introduction}

Recent traffic congestion of highways in many countries around the world has led railways to become the most popular means of public transportation, which has increased the demand for heavier and faster trains. An introduction of heavy axle loads (HALs) and high speed trains (HSTs) in modern railway traffic creates high stresses in track layers and causes excessive vibrations under train dynamic loading. As a consequence, the risk associated with train operation has increased significantly in the form of train safety, degradation/deformation of track foundations, fatigue failure of rails and interruption of power supply to trains (Madshus and Kaynia 2000). To avoid such risks and fulfil the demand of modern railway traffic, advanced design methods for ballasted railway track foundations are timely warranted and necessary.

Proper design of ballasted railway track foundations entails an accurate estimation of the thickness of granular layer in such a way that it can provide protection against subgrade failure and also limit the excessive track deformation induced by the train repeated moving loads. Granular layer thickness is defined as the combined thickness of ballast and sub-ballast between the sleeper bottom and subgrade surface, as shown in Fig. 1. Conventionally, the design of ballasted railway track foundations is referred to as design of granular layer thickness. Several empirical and simplified theoretical methods have been proposed in the literature to calculate the granular layer thickness, including the American Railway Engineering Association manual (AREA 1996); Canadian modified method suggested by Raymond (1978); Japanese National Railways method developed by Okabe (1961); British Railways method proposed by Heath et al. (1972); and UIC 719 R method offered by the International Union of Railways (1994). However, most of these methods are based on stress analyses in which all track layers were assumed to be homogeneous half-space with no 
allowance for the effect of stiffness of individual track layers. Furthermore, the effect of repeated loading on track settlement has not been included as a design parameter; thus, the application of these over-simplified methods for modern railway track design often provides ballpark estimates and may lead to poor design. The latest and probably the most robust design method currently available in the literature was developed two decades ago by Li and Selig (1998a, b), which relies on preventing the progressive shear failure and excessive plastic deformation of track subgrade. This method is based on a combined use of a multilayered analytical model called GEOTRACK with an extensive cyclic loading laboratory testing. The method has indeed provided some improvement in design of railway track foundations; however, frequent maintenance is still required for tracks designed using the most up-to-date standards that adopt either Li and Selig's method or other existing methods. Burrow et al. (2007) reported that the existing design methods may not be appropriate for modern railway traffics. Accordingly, there is an immense need to develop advanced design methods that can overcome and carefully consider the shortcoming of existing methods, leading to more reliable design.

This paper presents the development of a new promising design method for ballasted railway track foundations that overcomes most shortcomings of available design methods. The proposed method is based on modified empirical models and sophisticated 3D FE numerical analyses. The outcomes of the study are employed to develop design charts that form the core of the proposed method so as to facilitate the use of the method by practitioners.

\section{Development of new design method}

Over the years, the necessity to overcome the shortcomings of most available empirical and analytical approaches for design of railway track foundations has led to the development of 
numerical methods, which are facilitated by today's high processing capacity of computers. Different numerical modelling approaches have been used in the literature to study the behavior of railway track foundations [e.g., boundary elements (BE) method (Andersen and Nielsen 2003), finite elements (FE) method (Banimahd et al. 2013; El Kacimi et al. 2013; Hall 2003; Sayeed and Shahin 2015) and 3D FE-BE method (Adam et al. 2000; Galvín et al. 2010; O'Brien and Rizos 2005)]. Among these approaches, the FE method has been found to be the most useful tool for simulating the critical features of the train-track-ground interaction problem. However, there is still an immense need for a sophisticated three-dimensional (3D) FE numerical modelling approach for the development of an advanced design method that can overcome most shortcomings of existing methods, the current paper fills in this gap. The main features of available design methods' shortcomings that need to be overcome are discussed below.

In order to provide strong, safe, reliable, and efficient pathway for train traffic, the total track deformation should not exceed a prescribed tolerable limit (Shahin 2009). However, the critical factor in relation to deformation of granular layer is virtually overlooked in all available design methods, despite the fact that ballast can be responsible for up to $40 \%$ of total track deformation, as indicated by several researchers (Li et al. 2016; Stewart 1982). To avoid such limitation for an advanced design of track foundations, improved models capable of predicting both the deformation of ballast and subgrade materials should be developed. Furthermore, when a train runs along the track, the ballast and subgrade layers become subjected to complex loading condition involving principal stress rotation (Brown 1996; Powrie et al. 2007). Accordingly, the train moving loads (i.e., dynamic cyclic loading with principal stress rotation) may affect the material stiffness and degree of cumulative plastic strain (Inam et al. 2012; Lekarp et al. 2000a; Lekarp et al. 2000b). However, a serious shortcoming applied to most or all available design methods is that the subgrade stresses were 
calculated based on static loading that cannot fully capture the dynamic impact of the moving loads induced by trains.

Existing design methods also consider the effect of train speed by simply utilizing several empirical formulas for estimating the dynamic amplification factor (DAF). However, most available DAF empirical formulas only consider the impact of train speed and loading characteristics, and neglect the characteristics of the track-ground condition. Recent studies carried out by several researchers (e.g. Alves Costa et al. 2015; Sayeed and Shahin 2016a) indicated that the DAF is significantly influenced by the subgrade characteristics. Moreover, due to resonance, catastrophic track deflection may occur when the train speed approaches the critical speed (Krylov 1994; Madshus and Kaynia 1999; Yang et al. 2009), which is also significantly influenced by the modulus and thickness of the subgrade medium and train geometry (Alves Costa et al. 2015; Sayeed and Shahin 2016b). Unfortunately, there are currently no proper guidelines for considering the critical speed in any available design method. Again, such limitations emphasize the need for developing an advanced design method that can consider the DAF carefully, and can also provide guidelines to determine the critical speed of the train-track-ground system so as to avoid any undesirable failure scenario.

Inspired by the limitations discussed above, a new design method for railway track foundations is proposed in the current paper. To facilitate the use of the new design method by practitioners, a set of design charts that forms the core of the proposed method is developed. The design charts are based on the outcomes of advanced 3D FE analyses and modified empirical models. The affecting design parameters leading to the development of the design method is presented below.

\section{Design criteria}


Among several modes of track failures, the two major problems that increase the maintenance costs and reduce the riding quality are the subgrade progressive shear failure and excessive plastic deformation of the track. The focus of the new design method is directed to prevent the progressive shear failure at the subgrade surface and limit the excessive plastic deformation of the track under repeated train dynamic load. This means that the granular layer thickness should be sufficient so that the stress transferred to the subgrade through the granular media is less than an allowable value suitable for preventing both the subgrade progressive shear failure and excessive track deformation. Preventing the progressive shear failure at the top surface of subgrade (in the form of plastic flow) can be achieved by limiting the excessive cumulative plastic strain at the subgrade surface. On the other hand, limiting the excessive plastic deformation of the track can be achieved by limiting the total plastic deformation accumulated by both the ballast and subgrade sublayers. Accordingly, the design criteria for preventing the progressive shear failure and limiting the excessive track plastic deformation can be characterized by Equations (1) and (2), as follows:

$\varepsilon_{p_{-} s} \leq \varepsilon_{\left(p_{-} s\right) a}$

$\rho_{t}=\rho_{b}+\rho_{s} \leq \rho_{t a}$

where, $\varepsilon_{p_{-} s}$ is the cumulative plastic strain at the subgrade surface under repeated loading; $\varepsilon_{\left(p_{-} s\right) a}$ is the allowable plastic strain at the subgrade surface; $\rho_{t}$ is the total cumulative plastic deformation of the track under repeated train loading; $\rho_{b}$ and $\rho_{s}$ are the contribution to track deformation by the ballast and subgrade layers, respectively; $\rho_{t a}$ is the allowable plastic deformation of track for the design traffic tonnage. 
To fulfil the above design criteria, two strategies can be utilized: (1) improving the subgrade stiffness; and (2) decreasing the deviatoric stress transmitted to the subgrade by increasing the granular layer thickness. The second strategy is more practical and realistic, and will thus be the focus of this paper. For this strategy to be fulfilled in the proposed design method, a comprehensive study on the strain and deformation characteristics, and induced deviatoric stresses of the track substructure is essential, as described below.

\section{Strain and deformation characteristics of track substructure}

The subgrade progressive shear failure is most likely to occur in the ballast/subgrade interface, where the traffic induced stresses on the subgrade are very high due to the absence of an adequate granular layer thickness (Li 1994; Li and Selig 1995). Soil overstressing and repeated cyclic loading can lead to subgrade plastic flow from beneath the track towards the sideway and upward directions, and may cause bearing capacity failure. This phenomenon is known as "cess heave", which is presented in Fig. 2. In addition, the ballasted railway tracks settle as a result of the plastic deformations in the ballast layer and underlying subgrade soil caused by the repeated train moving loads. The plastic settlement developed by a single load application may be negligible under general condition; however, the total cumulative plastic settlement after millions of load cycles may develop to a significant extent that can severely affect the track performance. Moreover, the accumulation of the plastic settlement along and across the track is generally non-uniform, which may lead to undesirable changes in the track geometry.

Both the subgrade progressive shear failure and track plastic deformation occur due to the low stiffness of the ballast and subgrade soil that are subjected to repeated train moving loads. However, the progressive shear failure is mainly accompanied by an excessive plastic 
strain at the subgrade surface, whereas the excessive plastic deformation is influenced by the deformable ballast and subgrade layers combined. These two types of track failures can be prevented by providing a sufficient granular layer thickness between the sleeper and subgrade surface. Thereby, an accurate prediction of these two parameters is essential for proper design and maintenance planning of railway tracks. Consequently, for necessity of developing the new design method of ballasted railway track foundations, some improved empirical models for predicting the cumulative plastic strain and deformation of ballast and subgrade layers are described in this section, as presented below.

\section{Strain and deformation of ballast}

Over the years, a number of studies (e.g. Chrismer and Selig 1993; Indraratna and Salim 2003; Indraratna et al. 2001; Shenton 1975) have investigated the degradation and deformation behavior of ballast materials. These studies resulted in development of several empirical models for determining the accumulated plastic strain and deformation of ballast under repeated loading. However, most of these models were based on strain or deformation incurred after the first load cycle. Also, the applicability of these models is apparently limited to certain ballast types and conditions. Therefore, an improved empirical model that can predict the plastic deformation of ballast with consideration of the major influencing factors (i.e., stress state, physical state, type of ballast, and number of load cycles) is warranted and proposed in this paper. Such model is described below, which was found to give better predictions of the ballast accumulated plastic deformation.

For the stress state, many researchers (e.g. Alva-Hurtado 1980; Indraratna et al. 2010; Stewart 1982) have indicated that the deviatoric stress is the main stress factor influencing the cumulative plastic strain of ballast under repeated loading rather than the vertical stress or 
lateral confining stress alone. The plastic strain increases with the increase in the deviatoric stress, noting that the deviatoric stress, $\sigma_{d}$, is the difference between the major and minor principal stresses (i.e., $\sigma_{d}=\sigma_{1}-\sigma_{3}$ ). As the shear stress of ballast is basically half the deviatoric stress, the deviatoric stress can be considered to represent the physical condition of the shear stress. Therefore, the value of confining pressure, $\sigma_{3}$, is a secondary factor.

The physical state of ballast can be defined by its void ratio, gradation, moisture content, and ballast structure. Many test results (e.g. Indraratna and Salim 2003; Raymond and Diyaljee 1979) have reported significant effects of the ballast physical state on the cumulative plastic deformation. For example, the ballast materials having a small initial void ratio are stronger in shear and generate a smaller deformation than their counterparts having a higher initial void ratio. In order to consider the influence of the ballast physical state, it is neither useful nor common to include the ballast parameters such as the void ratio, gradation, moisture content, and ballast structure, directly into an empirical model. However, the influence of these parameters can rather be indirectly represented by the strength of ballast under monotonic triaxial loading tests. This is because the ballast strength depends on the void ratio, gradation, moisture content, and ballast structure. In addition, the monotonic triaxial tests can be routinely performed in any soil mechanics laboratory.

In this paper, an empirical model is proposed for predicting the ballast cumulative plastic strain, for three different types of ballast, namely basalt, granite, and dolomite. It should be noted that the model is a modified version of a previous model developed by the second author (i.e. Shahin 2009), and is based on data obtained from a series of large-scale triaxial, isotropically-consolidated, drained cyclic compression tests available in the literature (e.g. Alva-Hurtado 1980; Lackenby et al. 2007; Raymond and Williams 1978). The re-developed model is given as follows: 


$$
\varepsilon_{p_{-} b}=\frac{x(\alpha)^{y}\left[1+\ln \left(N_{b}\right)\right]^{z}}{100}
$$

where, $\varepsilon_{p_{-} b}$ is the cumulative plastic strain of ballast; $\alpha=\sigma_{d_{-} b} / \sigma_{s_{-} b}\left(\sigma_{d_{-} b}\right.$ is the applied cyclic deviatoric stress and $\sigma_{s_{-} b}$ is the compressive strength of ballast under $50 \mathrm{kPa}$ confining pressure, which can be obtained from a monotonic triaxial test); $N_{b}$ is the number of load applications on the ballast; and $x, y$ and $z$ are material parameters depend on the ballast type and given in Table 1. These parameters are determined from a regression analysis carried out on the data obtained from the cyclic triaxial loading tests conducted on the ballast. Fig. 3 shows the model calibration and predictions for different ballast types, including basalt [Fig. 3(a)], granite [Fig. 3(b)] and dolomite [Fig. 3(c)]. It can be seen that the influence of the stress state, physical state, and type of ballast on the cumulative plastic strain are well reflected in the model predictions.

For a particular ballasted railway track, the cumulative plastic strain of ballast, $\varepsilon_{p_{-} b}$, after $N_{b}$ load cycles can be determined by knowing the value of the deviatoric stress applied to the ballast layer, $\sigma_{d_{-} b}$. Then, the accumulation of plastic deformation can be determined by summing up the deformations of all subdivided layers, using the following equation:

$$
\rho_{b}=\sum \varepsilon_{\left(p_{-} b\right) i} H_{b i}
$$

where, $\rho_{b}$ is the plastic deformation of ballast layer; $\varepsilon_{\left(p_{-} b\right) i}$ is the plastic strain at the centre of each ballast sublayer; and $H_{b i}$ is the thickness of each sublayer of ballast. It is recommended to determine the deviatoric stress from a three dimensional (3D) finite 
elements (FE) numerical modelling, as will be described later. It should be noted that when a train passes along the track, the ballast particles are subjected to a complex loading that involves principal stress rotation. However, the empirical model developed above is based on data obtained from traditional cyclic triaxial tests in which the major principal stresses are not rotated. Therefore, it would be useful in the future to examine the deformation behavior of ballast under real loading conditions by considering cyclic loading with principal stress rotation, and incorporating this effect into the empirical model.

\section{Strain and deformation of subgrade}

In the past, a large number of cyclic loading triaxial or direct shear tests were conducted on either unsaturated or saturated soil samples under undrained or drained conditions, to investigate the plastic deformation of fine-grained soils for repeated loading. Based on experimental data collected from these tests, various models were proposed for estimating the cumulative plastic strain of fine-grained soils. Among these models, the most advanced ones that are currently used to predict the cumulative plastic strain and cumulative plastic deformation of track fine-grained subgrade soils are those developed by Li (1994) and Li and Selig (1996), as follows:

$$
\begin{aligned}
& \varepsilon_{p_{-} s}=\frac{a}{100}\left(\frac{\sigma_{d_{-} s}}{\sigma_{s_{-} s}}\right)^{m} N_{s}^{b} \\
& \rho_{s}=\sum \varepsilon_{\left(p_{-} s\right) i} H_{s i}
\end{aligned}
$$

where, $\varepsilon_{p_{-} s}$ is the cumulative plastic strain of the track subgrade soil; $\sigma_{d_{-} s}$ is the deviatoric stress applied to the subgrade; $\sigma_{s_{-} s}$ is the unconfined compressive strength of the subgrade 
soil; $N_{s}$ is the number of load repetitions applied to the subgrade layer; and $a, b$ and $m$ are material parameters given in Table $2 ; \rho_{s}$ is the cumulative plastic deformation of the track subgrade; $\varepsilon_{\left(p_{-} s\right) i}$ is the plastic strain at the center of each subdivided subgrade layer calculated using Equation (5); $H_{s i}$ is the thickness of each sublayer of the subgrade.

In Equation (5), the effect of the soil stress state (i.e., deviatoric stress) on the relationship between the cumulative plastic strain of the subgrade and number of load applications is considered directly. In addition, the influence of the soil physical state (e.g., water content, dry density, and soil structure) on the subgrade performance is represented indirectly by the static soil strength, $\sigma_{s_{-} s}$, which is directly linked to the soil physical state and its structure. The influence of the soil type is implied by the material parameters $(a, b$ and $m)$. Thus, the effect of all major influencing factors affecting the cumulative plastic strain of the subgrade soil (i.e., number of repeated stress applications, soil stress state, soil type, and soil physical state) are reflected in the developed prediction model. Therefore, the empirical model adopted in Equation (5) is used in the current work for development of the design charts that will be described later.

\section{Deviatoric stress characteristics of track substructure}

A key element in the development of ballasted railway track design method is the accurate calculation of distribution of deviatoric stress caused by true train moving loads in the granular and subgrade layers under various train-track-ground conditions, including the moduli and thicknesses of ballast and subgrade. To this end, this section is devoted to the analyses of the deviatoric stress generation within the track foundation using an advanced 
three-dimensional (3D) finite elements (FE) numerical modelling subjected to true train moving loads, as explained below.

The 3D FE numerical model developed in this paper was previously established by the authors (Sayeed and Shahin 2015; Sayeed and Shahin 2016b) and validated against data of field measurements obtained from Cunha and Correia (2012) and Kaynia et al. (2000). The 3D FE numerical model is used herein to investigate the dynamic response of the train-trackground system subjected to train moving loads, for the deviatoric stress analyses, which is shown in Fig. 4. The dimensions of the 3D FE model are $80 \mathrm{~m}, 36 \mathrm{~m}$, and $7.5 \mathrm{~m}$ in the longitudinal, horizontal, and vertical directions, respectively. The rail is modelled using onedimensional (1D) I-beam section running across the length of the modelled track. A UIC 60 section is assumed for the rail, which is fixed to the sleepers by rail pads characterized by an elastic link (spring-like) element of stiffness equal to $100 \mathrm{MN} / \mathrm{m}$. All other track components (i.e., sleeper, ballast, interface, and subgrade) are modelled using 3D solid elements, and it is assumed that the granular layer is characterized only by the ballast layer. For the model geometry, a total of 133 sleepers are placed along the rail at $0.6 \mathrm{~m}$ interval. The ballast layer is modelled using elastoplastic Mohr-Coulomb (MC) materials, whereas the other track materials are considered to be linear elastic (LE) materials. The material properties of the track model are given in Table 3 , and the range of variables considered are given in Table 4.

The element size of the FE model is generally estimated based on the smallest wavelength that allows the high frequency motion to be simulated correctly. Accordingly, the sizes of the 3D finite elements in the current study are taken to be: $0.167 \mathrm{~m} \times 0.137 \mathrm{~m} \times 0.2 \mathrm{~m} ; 0.2 \mathrm{~m} \times$ $0.2 \mathrm{~m} \times 0.2 \mathrm{~m}$; and $0.6 \mathrm{~m} \times 0.6 \mathrm{~m} \times 0.6 \mathrm{~m}$ for the sleepers, ballast, and subgrade, respectively. Overall, the FE mesh is consisted of 285,000 elements. The model vertical boundaries are connected to viscous dampers to absorb the incident $S$ - and $P$ - waves so as to 
represent infinite boundary conditions, as suggested by many researchers (e.g. Kouroussis et al. 2011; Lysmer and Kuhlemeyer 1969). The nodes at the bottom boundary are set to be fixed in every direction to simulate a bedrock. The material damping of the FE model is characterized by the mass and stiffness proportional coefficients, normally referred to as the Rayleigh damping, which is commonly used in the dynamic analyses.

In the current analyses, the standard X-2000 passenger train is considered to be moving along the modelled track, and the approach of simulating the moving loads is taken to be the same as that described in previous papers published by the authors (Sayeed and Shahin 2016a, b). The train geometry and standard axle loads of the X-2000 high speed train (HST) are summarized in Table 5, including (for each car number) the distance between axles $\left(L_{a}\right)$, distance between two bogies $\left(L_{b}\right)$, carriage length $\left(L_{c}\right)$, front wheel load $\left(P_{F}\right)$ and rear wheel load $\left(P_{R}\right)$. Fig. 5 shows a schematic diagram of the X-2000 HST and its components.

\section{Distribution of deviatoric stress along the rail}

The characteristics of the deviatoric stress distribution along the rail at the ballast surface (i.e., zero depth below the sleeper bottom) and at the subgrade surface (i.e., below the granular layer) are shown in Fig. 6. It can be seen from Fig. 6(a) that the maximum deviatoric stresses induced at the ballast surface beneath the sleepers are almost constant after the passage of the X-2000 HST along the track. However, the deviatoric stresses at the same depth of the ballast below the crib are less than those beneath the sleeper. On the other hand, it can be seen from Fig. 6(b) that the deviatoric stress distribution along the rail at the subgrade surface is almost invariant. However, for the purpose of design of railway track foundations, the deviatoric stress distribution along the depth of the ballast and subgrade 
layers can be selected below the sleeper rather than the crib, which is the zone of the maximum deviatoric stress.

\section{Distribution of deviatoric stress along the sleeper}

Fig. 7 shows the deviatoric stress distribution along the sleeper at four different depths of ballast [Fig. 7(a)] and three different depths of subgrade [Fig. 7(b)] from the sleeper bottom. It can be seen from Fig. 7(a) that the deviatoric stress of the ballast at various depths bellow the sleeper is minimum at the track centre and maximum at the sleeper end. However, the variation of the deviatoric stress distribution along the sleeper reduces with the depth below the sleeper. Similarly, it can be seen from Fig. 7(b) that the deviatoric stress at a depth equal to $0.45 \mathrm{~m}$ below the sleeper bottom (i.e., at the subgrade surface) is maximum at the end of the sleeper. However, with the increase in depth below the sleeper bottom, the distribution of the deviatoric stress in the subgrade along the sleeper becomes almost uniform. Therefore, for the purpose of design of railway track foundations, it can be considered that the maximum deviatoric stress occurs below the sleeper end.

\section{Effect of ballast and subgrade stiffness on deviatoric stress}

Fig. 8 presents the distribution of the maximum deviatoric stress with depth in the granular layer for various substructure conditions, including the ballast modulus [Fig. 8(a)] and subgrade modulus [Fig. 8(b)]. It can be seen from Fig. 8(a) that the deviatoric stress diminishes with the depth of granular layer, for all ballast modulus. However, the stress dissipation is not the same; it is higher for stiffer ballast. It can also be seen that the deviatoric stress developed at the ballast surface is greater for higher ballast modulus. On the other hand, it can be seen from Fig. 8(b) that the deviatoric stress induced at the ballast surface increases with the decrease of the subgrade stiffness, indicating a significant stress generation 
in the ballast layer supported by the soft subgrade, which might increase the ballast particle breakage and can lead to ballast fouling. It can also be seen that the stress distribution efficiency for the ballast layer is higher when the subgrade is softer.

Fig. 9 presents the distribution of deviatoric stress with depth in the subgrade layer, for various substructure conditions, including the ballast modulus [Fig. 9(a)] and subgrade modulus [Fig. 9(b)]. It can be seen from Fig. 9(a) that an increase in the ballast modulus decreases the deviatoric stress, at all depths within the subgrade layer. On the contrary, it can be seen from Fig. 9(b) that an increase in the subgrade modulus significantly increases the deviatoric stress at the subgrade surface. However, the difference in the deviatoric stress (due to different subgrade stiffness) at each depth below the sleeper bottom decreases with depth.

\section{Effect of granular layer thickness on deviatoric stress}

The impact of granular layer thickness, $H_{b}$, on the distribution of deviatoric stress with depth for the subgrade is investigated by considering a range of ballast thicknesses from $0.15 \mathrm{~m}$ to $1.35 \mathrm{~m}$. The impact of the granular layer thickness on the deviatoric stress distribution within the subgrade is studied for two type of subgrade materials, including the soft subgrade [Fig. 10(a)] and stiff subgrade [Fig. 10(b)]. The soft subgrade is characterized herein by a dynamic subgrade modulus equal to $15 \mathrm{MPa}$, while the stiff subgrade is represented by a dynamic modulus of $120 \mathrm{MPa}$. It can be seen from Fig. 10 that the increase in the granular layer thickness leads to a significant reduction in the deviatoric stress at the subgrade surface. It is also evident from Fig. 10(a) that a significant difference in the deviatoric stress occurs at each depth below the bottom of sleeper due to the corresponding difference in the granular layer thickness, and this difference reduces with the distance below the sleeper. However, in contrast to the soft subgrade condition, Fig. 10(b) shows that the difference in the deviatoric 
stress due to the change in the granular layer thickness below the bottom of sleeper is almost negligible in the case of stiff subgrade for all depths. In essence, the increase in the granular layer thickness reduces the distribution of the deviatoric stress within the subgrade in two ways. Firstly, when the granular layer thickness increases, the distance of the subgrade surface below the bottom of sleeper is automatically increased. Consequently, the deviatoric stress at the subgrade surface is automatically decreased by virtue of the depth spreading effect. Secondly, with the increase of the granular layer thickness (i.e., stiffer layer), the stress spreading effect also increases, which leads to a reduction in the deviatoric stress at all depths in the subgrade. However, the second effect weakens when the difference in the stiffness of the granular and subgrade layers becomes smaller. Therefore, when the subgrade soil modulus is closer to that of the ballast, the effect of the granular layer thickness on the distribution of the deviatoric stress in the subgrade becomes insignificant.

\section{Effect of subgrade layer thickness on deviatoric stress}

The impact of the subgrade layer thickness on the distribution of deviatoric stress within the subgrade is investigated by considering three different subgrade thicknesses (i.e., $H_{s}=3.5 \mathrm{~m}$, $7.0 \mathrm{~m}$, and $10 \mathrm{~m}$ ), overlying a hard rock, and the results are shown in Fig. 11. It can be seen that the difference in the deviatoric stress at each depth of the subgrade is negligible, except at the interface of the subgrade with the hard rock. As the influence of the subgrade thickness on the distribution of the deviatoric stress in the subgrade is insignificant, the subgrade thickness is assumed to be fixed at $7.0 \mathrm{~m}$ in the deviatoric analysis performed for development of the design charts used in the proposed design method. 


\section{Traffic parameters}

The proposed design method for ballasted railway track foundations emphasizes the influence of the following traffic parameters on the track performance: wheel spacing, train speed, and traffic tonnage. For the purpose of presenting the effects of the abovementioned traffic parameters on the track performance, the 3D FE model of the X-2000 HST (Fig. 4) and its track properties (Table 3) described earlier are used.

The impact of the train wheel spacing on the track dynamic response is investigated and presented in this section, which has been later incorporated in the track design procedures described in the companion paper, i.e., Part II: Applications (Sayeed and Shahin 2017). For this purpose, six different values of wheel spacing (i.e., $L_{a}=1.6,1.8,2.2,2.6,3.0$, and $3.4 \mathrm{~m}$ ) are considered for the X-2000 HST. This range of wheel spacing is selected carefully to reflect the practical range expected in major trains including freight and high speed passenger trains (Colaço et al. 2016; Jeffs and Tew 1991). The influence of wheel spacing on the track deflection is shown in Fig. 12. It can be seen from Fig. 12(a) that the track deflection increases with the decrease in the wheel spacing, as expected. To quantify the impact of the wheel spacing in the proposed design method, a relationship between the wheel spacing and wheel spacing factor (WSF) is developed and presented in Fig. 12(b). The WSF is defined as the ratio of track deflection at particular wheel spacing to track deflection at the standard wheel spacing for the X-2000 HST. It can be seen from Fig. 12(b) that the effect of wheel spacing can be reduced significantly by increasing the spacing between the train wheels.

Available design methods usually consider the effect of train speed and loading characteristics by simply utilizing several empirical formulas that neglect the characteristics of subgrade conditions. However, it was found by Sayeed and Shahin $(2016 a, b)$ that the 
track response is significantly influenced by the subgrade stiffness and thickness. Therefore, for development of the new design method, the effects of train speed on the track performance are investigated under various subgrade conditions and has been later incorporated in the track design procedures described in the companion paper (i.e., Part II: Applications). Five different values of subgrade modulus (i.e., $E_{s}=15,30,60,90$, and 120 $\mathrm{MPa}$ ) and four different track subgrade thicknesses (i.e., $H_{s}=5,7.5,10$, and $\infty \mathrm{m}$ ) overlying a hard bedrock are utilized. The results are presented in Fig. 13 in terms of the relationship between train speed and dynamic amplification factor (DAF). The DAF is defined as the ratio of the maximum dynamic sleeper deflection at a particular train speed to the maximum quasistatic sleeper deflection (i.e., sleeper deflection at a train speed of $5 \mathrm{~m} / \mathrm{s}$ ). Fig. 13 shows the evolution of the dynamic amplification factor for the sleeper downward deflection versus train speed, for different subgrade stiffness and subgrade thickness. It can be seen that, for all values of $E_{s}$ and $H_{s}$, the DAF increases with the increase in the train speed until it reaches a peak value corresponding to the critical speed, after which it decreases with further increase in the train speed. Fig. 13 also indicates that the DAF decreases with the increase in both the subgrade stiffness and thickness. On the other hand, the magnitude of the critical speed increases with the increase in the subgrade stiffness, while it decreases with the increase in the subgrade thickness. The practical implication of this finding is that the localized ground improvement of the soft subgrade can be very beneficial in decreasing the DAF and increasing the critical speed of trains.

The design traffic tonnage is the total possible amount of load in million gross tonnes (MGT) that needs to be carried along the track without causing track failure. This value should be selected based on the maintenance costs and traffic speed restriction considerations. The traffic parameters mentioned earlier are used to calculate three design variables for the design traffic tonnage: (1) dynamic wheel load, $P_{d} ;(2)$ total equivalent number of load applications 
in the ballast layer, $N_{b}$; and (3) total equivalent number of load applications in the subgrade layer, $N_{s}$. The design dynamic wheel load corresponding to the maximum static wheel load, train speed, and wheel spacing of the moving train can be determined as follows:

$P_{d}=P_{s} \times \mathrm{WSF} \times \mathrm{DAF}$

where, $P_{d}$ is the design dynamic wheel load; $P_{s}$ is the maximum static wheel load of the train, assumed to run along the track; WSF is the wheel spacing factor [Fig. 12(b)] based on the impact of the wheel spacing of any train with respect to the standard wheel spacing of the X2000 HST; and DAF is the dynamic amplification factor based on the train speed and subgrade condition (Fig. 13).

It is generally assumed that when a train runs along the track, two axles under the same bogie produce one load cycle in the ballast layer whereas four axles under two adjacent bogies (carriages) produce a single load cycle in the subgrade layer (Li et al. 2016). Therefore, for any particular wheel load, $P_{s i}$, the number of load cycles in the ballast, $N_{b i}$, and in the subgrade, $N_{s i}$, can be determined as follows:

$N_{b i}=\frac{T_{i}}{4 P_{s i}}$

$$
N_{s i}=\frac{T_{i}}{8 P_{s i}}
$$

where, $T_{i}$ is the total traffic tonnage of the wheel load, $P_{s i}$, in the same unit of $P_{s i}$. In order to consider the influence of different amplitudes of wheel loading on subgrade performance, the 
number of load cycles in the subgrade, $N_{s i}$, for wheel loading, $P_{s i}$, can be converted to an equivalent number of load cycles, $N_{s i}^{o}$, of the maximum static wheel load, $P_{s}$, as follows (Li and Selig 1996):

$$
N_{s i}^{o}=N_{s i}\left(\frac{P_{s i}}{P_{s}}\right)^{m / b}
$$

where, $m$ and $b$ are material parameters dependent on the subgrade soil type (Table 2). Similarly, the number of load cycles in the ballast, $N_{b i}$, for wheel load, $P_{s i}$, can be converted to an equivalent load cycle, $N_{b i}^{o}$, corresponding to the maximum static wheel load, $P_{s}$, as follows:

$$
N_{b i}^{o}=N_{b i}\left(\frac{P_{s i}}{P_{s}}\right)^{y / z}
$$

where, $y$ and $z$ are material parameters dependent on the ballast type (given in Table 1). Accordingly, the total number of equivalent load applications in both the ballast layer $\left(N_{b}\right)$ and subgrade layer $\left(N_{s}\right)$ corresponding to the maximum static wheel load, $P_{s}$, can be calculated as follows:

$$
N_{b}=N_{b i}^{o}+N_{b i}^{1}+N_{b i}^{2}+N_{b i}^{3}+----+N_{b i}^{n}
$$

$$
N_{s}=N_{s i}^{o}+N_{s i}^{1}+N_{s i}^{2}+N_{s i}^{3}+----+N_{s i}^{n}
$$




\section{Design principles and options}

As mentioned earlier, the two criteria that need to be achieved for design of railway track foundations are: (1) limiting the cumulative plastic strain at the subgrade surface; and (2) limiting the total plastic deformation of the track layers to a value below a tolerable level, as represented earlier by Equations (1) and (2). The procedures that need to be followed to achieve an appropriate design using the above two design criteria are explained in this section. For convenience, the distinction between the ballast and sub-ballast is ignored by simply presenting the ballast layer as the granular layer.

For particular loading conditions and characteristics of the granular and subgrade layers, the design of ballasted railway track is relevant to selecting an adequate granular layer thickness so that the deviatoric stress experienced by the substructure layers is adequately low. Thus, the possibility of occurrence of the progressive shear failure at the subgrade surface and excessive plastic deformation of the track can be prevented. Based on this principle, the first phase of developing the railway track design charts involves determining the deviatoric stresses in the ballast and subgrade, for a range of granular layer and subgrade conditions. Calculation of the deviatoric stress is performed using the advanced $3 \mathrm{D}$ FE modelling subjected to quasistatic (i.e., at speed $=5 \mathrm{~m} / \mathrm{s}$ ) train moving loads of the X-2000 HST, for a total number of 105 cases with various combinations of ballast and subgrade characteristics. The parameters assumed include the ballast modulus (i.e., $E_{b}=135,270$, and $540 \mathrm{MPa}$ ), subgrade soil modulus (i.e., $E_{s}=15,30,60,90$, and $120 \mathrm{MPa}$ ) and granular layer thickness (i.e., $H_{b}=0.15,0.30,0.45,0.60,0.75,1.05$, and $1.35 \mathrm{~m}$ ). The other track parameters are fixed at their nominal values given earlier in Table 3 . The ranges selected above and those in Table 
3 for all material parameters are selected carefully to reflect the practical range expected in major railway tracks ( $\mathrm{Li}$ 1994; Li and Selig 1994). It should be noted that although the deviatoric stresses for development of the design charts are calculated based on a specific train geometry (i.e., X-2000 HST wheel spacing) and train speed (i.e., $5 \mathrm{~m} / \mathrm{s}$ ), the impact of any other train geometry or train speed are incorporated later in the design procedure so that the design charts can be used universally for any train loading conditions.

\section{Design for preventing progressive shear failure}

The design criterion for preventing the progressive subgrade failure is to limit the cumulative plastic strain at the subgrade surface below an allowable value. As indicated earlier in Equation (5), the principle of keeping the cumulative plastic strain below a certain tolerable level means limiting the deviatoric stress. The deviatoric stress at the subgrade surface for different substructure conditions is readily calculated using the earlier developed 3D FE modelling. Since the calculation of the deviatoric stress assumes linear elastic-plastic ballast and linear elastic subgrade, the ratio of the deviatoric stress to the design dynamic wheel load is set to be constant for a given track-ground condition. For illustration, the time history responses for the deviatoric stress and strain at the subgrade surface under three different amplitudes of loading for the X-2000 HST (i.e., 100\%, 150\%, and 200\% of the standard X2000 HST) are depicted in Fig 14. It can be seen that both the deviatoric stress [Fig 14(a)] and deviatoric strain [Fig 14(b)] under the passing wheel loads increase with the increase of the loading amplitudes. The obtained results indicated that the maximum deviatoric stress and strain increase linearly with the loading amplitudes, which allowed the development of the following dimensionless strain influence factor: 
$I_{\varepsilon}=\frac{\sigma_{d} \times A}{P_{d}}$

where, $I_{\varepsilon}$ is the strain influence factor; $\sigma_{d}$ is the deviatoric stress; $P_{d}$ is the design dynamic wheel load, which can be calculated using Equation (7); $A$ is an area coefficient to make the strain influence factor dimensionless ( $A$ unit value $1 \mathrm{~m}^{2}$ is assumed for the ease of calculation).

The strain influence factor generated at the subgrade surface, $I_{\varepsilon_{-}}$, from the FE analyses for various substructure conditions can now be readily synthesized into simple design charts, which are built to calculate the granular layer thickness needed to prevent the progressive shear failure. An example of these design charts is shown in Fig. 15, in which each curve corresponds to a particular ballast and subgrade moduli. The complete set of design charts encompassing other design parameters are given in Appendix $A$ of the companion paper (i.e., Part II: Applications), which are employed to calculate the granular layer thicknesses for four track sites and the results were compared with field measurements.

The development process of the relationship between the granular layer thickness, $H_{b}$, and strain influence factor at the subgrade surface, $I_{\varepsilon_{-} s}$, is illustrated in Fig. 16. As the process for a certain combination of $E_{b}$ and $E_{s}$ is identical, only the establishment of curve 'a' of Fig. 15 for the substructure with a specific modulus of ballast and subgrade (i.e., $E_{b}=270 \mathrm{MPa}$ and $E_{s}=15 \mathrm{MPa}$ ) is shown in Fig. 16. For this purpose, Fig. 16(a) is first regenerated from Fig. 10a by simply replacing the deviatoric stress with the strain influence factor using Equation (14). It can be seen from Fig. 16(a) that the strain influence factor at the subgrade surface, $I_{\varepsilon_{-} s}$, decreases with the increase of the granular layer thickness, $H_{b}$. In order to develop the 
design charts, the resulting strain influence factors at the subgrade surface, $I_{\varepsilon_{-} s}$, are plotted against $H_{b}$ for a particular set of granular layer and subgrade moduli, as shown in Fig. 16(b).

To apply the proposed design method using the design charts (e.g., Fig. 15), the minimum required thickness of the granular layer can be determined for an acceptable value of the subgrade surface strain influence factor, $I_{\left(\varepsilon_{-} s\right) a}$. Therefore, the value of $I_{\left(\varepsilon_{-} s\right) a}$ needs to be determined using Equation (15) below, obtained by rearranging Equation (14) and substituting $I_{\left(\varepsilon_{-} s\right) a}$ and $\sigma_{\left(d_{-} s\right) a}$ for $I_{\varepsilon}$ and $\sigma_{d}$, respectively, as follows:

$I_{\left(\varepsilon_{-} s\right) a}=\frac{\sigma_{\left(d_{-} s\right) a} \times A}{P_{d}}$

where, $I_{\left(\varepsilon_{-} s\right) a}$ is the allowable strain influence factor at the subgrade surface; $\sigma_{\left(d_{-} s\right) a}$ is the allowable deviatoric stress at the subgrade surface; $P_{d}$ is the design dynamic wheel load, can be calculated using Equation (7); and $A$ is the area coefficient $\left(=1 \mathrm{~m}^{2}\right)$. In addition, the allowable deviatoric stress at the subgrade surface, $\sigma_{\left(d_{-} s\right) a}$, can be calculated using Equation (16) below, which is derived by rearranging Equation (5) and substituting $\sigma_{\left(d_{-} s\right) a}$ and $\varepsilon_{\left(p_{-} s\right) a}$ for $\sigma_{d_{-} s}$ and $\varepsilon_{p_{-} s}$, respectively, as follows:

$\sigma_{\left(d_{-} s\right) a}=\left(\frac{\varepsilon_{\left(p_{-} s\right) a}}{a N_{s}^{b}}\right)^{\frac{1}{m}} \sigma_{s_{-} s} \times 100$

where, $\sigma_{\left(d_{-} s\right) a}$ is the allowable deviatoric stress at the subgrade surface; $\varepsilon_{\left(p_{-} s\right) a}$ is the allowable cumulative plastic strain at the subgrade surface needed for preventing the 
progressive shear failure; $\sigma_{s_{-} s}$ is the soil compressive strength; $a, b$ and $m$ are the material parameters pertinent to the subgrade soil type (Table 2); $N_{s}$ is the total equivalent number of repeated applications of the design load on the subgrade.

Design for preventing excessive plastic deformation

The key principle of preventing the excessive plastic deformation in the track means limiting the track deformation to a value below a tolerable level. Therefore, the total cumulative plastic deformation due to repeated loading in the substructure layers, $\rho_{t}$, (i.e., granular ballast layer thickness, $H_{b}$, and subgrade layer thickness, $H_{s}$ ) need to be determined by summing the integration of the cumulative plastic strain of ballast (i.e., Equation 3) and subgrade (i.e., Equation 5) layers, as follows:

$\rho_{t}=\rho_{b}+\rho_{s}=\int_{0}^{H_{b}} \frac{x\left[1+\ln \left(N_{b}\right)\right]^{z}}{100}\left(\frac{\sigma_{d_{-} b}}{\sigma_{s_{-} b}}\right)^{y} d h+\int_{0}^{H_{s}} \frac{a N_{s}^{b}}{100}\left(\frac{\sigma_{d_{-} s}}{\sigma_{s_{-} s}}\right)^{m} d h$

Rearranging Equation (17) yields:

$\rho_{t}=\frac{x\left[1+\ln \left(N_{b}\right)\right]^{z}}{100}\left(\frac{P_{d}}{A \sigma_{s_{-} b}}\right)^{y} \int_{0}^{H_{b}}\left(\frac{A \sigma_{d_{-} b}}{P_{d}}\right)^{y} d h+\frac{a L N_{s}^{b}}{100}\left(\frac{P_{d}}{A \sigma_{s_{-} s}}\right)^{m} \int_{0}^{H_{s}}\left(\frac{A \sigma_{d_{-} s}}{P_{d}}\right)^{m} \frac{d h}{L}$

Using the definition of the strain influence factor (i.e., Equation 14), Equation (18) can be expressed as follows:

$\rho_{t}=\frac{x\left[1+\ln \left(N_{b}\right)\right]^{z}}{100}\left(\frac{P_{d}}{A \sigma_{s_{-} b}}\right)^{y} \int_{0}^{H_{b}}\left(I_{\varepsilon_{-} b}\right)^{y} d h+\frac{a L N_{s}^{b}}{100}\left(\frac{P_{d}}{A \sigma_{s_{-} s}}\right)^{m} \int_{0}^{H_{s}}\left(I_{\varepsilon_{-} s}\right)^{m} \frac{d h}{L}$ 
As indicated by Equation (19), the deformation of the track substructure layers is a function of the strain influence factor, which is a function of the deviatoric stress in the ballast and subgrade. Therefore, the deviatoric stress distribution with depth within the ballast and subgrade layers for different substructure conditions is readily calculated using the earlier developed 3D FE modelling subjected to the moving loads of the X-2000 HST. Afterwards, the results are presented in terms of the distribution of strain influence factor with depth using Equation (14). Fig. 17 shows an example of the distribution of the dimensionless strain influence factor, $I_{\varepsilon_{-} b}$, with depth in the ballast layer for a particular ballast modulus (i.e., $E_{b}$ $=270 \mathrm{MPa}$ ) and thickness (i.e., $H_{b}=0.45 \mathrm{~m}$ ) for different values of the subgrade modulus. It should be noted that Fig. 17 is simply a reproduction of Fig. 8(b), in which the axis of the deviatoric stress is replaced by the strain influence factor using Equation (14). Similarly, the distribution of $I_{\varepsilon_{-} b}$ with depth in the ballast layer for different substructure conditions (i.e. different moduli and thicknesses of ballast and subgrade) are presented in Appendix B of the companion paper (Part II: Applications).

The deformation generated in the ballast layer, $\rho_{b}$, for the associated track substructure conditions can be determined using the results of Appendix B (e.g., Fig. 17) and the following equation, which is the first part of Equation (19):

$$
\rho_{b}=\frac{x\left[1+\ln \left(N_{b}\right)\right]^{z}}{100}\left(\frac{P_{d}}{A \sigma_{s_{-} b}}\right)^{y} \int_{0}^{H_{b}}\left(I_{\varepsilon_{-} b}\right)^{y} d h
$$

The integration in Equation (20) can be solved by dividing the granular ballast layer into sublayers of thicknesses $=0.1-0.15 \mathrm{~m}$, then the integration is obtained by summing the 
multiplication of the strain influence factor at the middle of each sublayer by the corresponding sublayer thickness.

In order to develop the design charts for preventing the excessive plastic deformation of track, the second part of Equation (19), which quantifies the cumulative plastic deformation of the subgrade layer can be rearranged as follows:

$\rho_{s}=\frac{a L N_{s}^{b}}{100}\left(\frac{P_{d}}{A \sigma_{s_{-} s}}\right)^{m} \int_{0}^{H_{s}}\left(I_{\varepsilon_{-} s}\right)^{m} \frac{d h}{L}=\left[\frac{a L N_{s}^{b}}{100}\left(\frac{P_{d}}{A \sigma_{s_{-} s}}\right)^{m}\right] I_{\rho_{-} s}$

thus;

$$
I_{\rho_{-} s}=\int_{0}^{H_{s}}\left(I_{\varepsilon_{-} s}\right)^{m} \frac{d h}{L}
$$

where, $I_{\rho_{-} s}$ is a dimensionless deformation influence factor. It should be noted that both the area coefficient $(A)$ and length coefficient $(L)$ are used in Equations (18-22) for the purpose of non-dimensionalizing the strain and deformation influence factors. Similar to the area coefficient, a unit value is assumed for the length coefficient (i.e., $L=1 \mathrm{~m}$ ) for the ease of calculation.

As indicated in Equation (22), the subgrade deformation influence factor, $I_{\rho_{-} s}$, is a function of the distribution of the strain influence factor, $I_{\varepsilon_{-} s}$, with the depth of subgrade, type of subgrade, and thickness of subgrade, $H_{s}$. It should be noted that the distribution of $I_{\varepsilon_{-} s}$ with depth in the subgrade is governed by different combinations of $E_{b}, E_{s}$, and $H_{b}$. Accordingly, 
the values of $I_{\rho_{-} s}$ are calculated using Equation (22) and the distribution of strain influence factor, $I_{\varepsilon_{-} s}$, with depth of the subgrade for different combinations of $E_{b}, E_{s}, H_{b}$, and $H_{s}$, and the parameter $m$ depends on the subgrade soil type. In order to produce the design charts, the values of the resulting $I_{\rho_{-} s}$ are plotted against $H_{b}$ for particular granular ballast and subgrade layer conditions. Fig. 18 shows two samples of the design charts that can be used to calculate the granular layer thickness needed to prevent the excessive plastic deformation. Each chart corresponds to one soil type and one modulus combination of the granular and subgrade layers, and each curve corresponds to one deformable subgrade layer thickness. Following the same process mentioned above, a total of 60 design charts are developed and given in Appendix $C$ of the companion paper (i.e., Part II: Applications).

To apply the proposed design method for estimating the granular layer thickness, the first step is to determine the cumulative plastic deformation in the initially assumed thickness of the granular ballast layer, $\rho_{b}$, as explained above. Then, the allowable subgrade deformation influence factor, $I_{\left(\rho_{-} s\right) a}$, needs to be calculated using Equation (23) below, obtained by rearranging Equation (21) and substituting $\left(\rho_{t}-\rho_{b}\right)$ for $\rho_{s}$ and $\rho_{t a}$ for $\rho_{t}$, as follows:

$$
I_{\left(\rho_{-} s\right) a}=\frac{\rho_{t a}-\rho_{b}}{\frac{a L N_{s}^{b}}{100}\left(\frac{P_{d}}{A \sigma_{s_{-} s}}\right)^{m}}
$$

where, $\rho_{t a}$ is the allowable track deformation; $\rho_{b}$ is the contribution of track deformation of the ballast layer; $N_{s}$ is the total equivalent number of load repetitions in the subgrade for the design traffic tonnage; $P_{d}$ is the design dynamic wheel load; $\sigma_{s_{-} s}$ is the unconfined compressive strength of subgrade soil; $a, b$ and $m$ are material parameters dependent on the 
subgrade soil type (see Table 2$) ; A$ is the area coefficient $\left(=1 \mathrm{~m}^{2}\right)$; and $L$ is the length coefficient $(=1 \mathrm{~m})$.

After determining $I_{\left(\rho_{-} s\right) a}$, the required granular layer thickness, $H_{b}$, can be obtained using the relevant design chart [e.g., Fig. 18(a)] from Appendix $C$ given in the companion paper (i.e., Part II: Applications), based on the specific data of ballast modulus, $E_{b}$, subgrade modulus, $E_{s}$, subgrade layer thickness, $H_{s}$, and subgrade soil type. If the thickness obtained from the design chart is not equal to the initially assumed granular layer thickness, $H_{b}$, the steps of calculating $\rho_{b}$ for an obtained thickness, $I_{\left(\rho_{-} s\right) a}$, and $H_{b}$ should be repeated until the granular layer thickness considered in the calculation of $\rho_{b}$ converges with the thickness obtained from the design charts.

Full details in relation to the procedures of using the design method for calculating $H_{b}$ utilizing the developed design charts and applications of the new design method to real track situations are described in detail in the companion paper (i.e., Part II: Applications).

\section{Summary and conclusions}

In this paper, a new practical design method for ballasted railway track foundations was developed to overcome most shortcomings of the existing design methods. The proposed method was meant to prevent two common track failures, namely the subgrade progressive shear failure and excessive track deformation. The proposed design method was developed based on improved empirical models and sophisticated three-dimensional (3D) finite element (FE) numerical analyses. The improved empirical models were used for predicting the cumulative plastic deformation of the track, whereas the stress behavior of ballast and subgrade under applications of train repeated loadings were determined from the $3 \mathrm{D} F E$ 
numerical modelling. In the improved empirical models, the effects of number of load applications, stress state, physical state and material type were considered. The impact of stress state was explicitly represented by the induced deviator stress while the material physical state was indirectly specified by its monotonic strength obtained from the conventional triaxial compression tests. The material type was considered through certain material parameters involved. In the 3D FE modelling, the dynamic response of railway tracks under a variety of train-track-ground conditions was investigated and quantified. The practical implications of the obtained results were critically analysed and discussed to facilitate the development of the proposed design method.

The results obtained from the study were synthesized into a set of design charts that formed the core of the proposed design method so that the method can be readily used by railway geotechnical engineers for routine design practice. All governing parameters that significantly affect the selection of the granular layer thickness for preventing the track failure were carefully considered in the proposed design method. The verification and application of the proposed design method were presented in a companion paper (i.e., Part II: Applications) and the results were found to be in excellent agreement with field observations. It is believed that the proposed design method is expected to provide a significant contribution to the current railway track code of practice. 


\section{References}

Adam, M., Pflanz, G., and Schmid, G. 2000. Two- and three-dimensional modelling of halfspace and train-track embankment under dynamic loading. Soil Dynamics and Earthquake Engineering 19(8): 559-573. doi: Doi 10.1016/S0267-7261(00)00068-3.

Alva-Hurtado, J.E.D. 1980. A methodology to predict the elastic and inelastic behavior of railroad ballast. In Department of Civil Engineering. University of Massachusetts, Amherst, Massachusetts, USA.

Alves Costa, P., Colaço, A., Calçada, R., and Cardoso, A.S. 2015. Critical speed of railway tracks. Detailed and simplified approaches. Transportation Geotechnics 2: 30-46. doi: http://dx.doi.org/10.1016/j.trgeo.2014.09.003.

Andersen, L., and Nielsen, S.R. 2003. Boundary element analysis of the steady-state response of an elastic half-space to a moving force on its surface. Engineering Analysis with Boundary Elements 27(1): 23-38. doi: Pii S0955-7997(02)00096-6.

AREA. 1996. Manual for Railway Engineering. Vol 1, American Railway Engineering Association (AREA), Washington, D.C.

Banimahd, M., Woodward, P., Kennedy, K.J., and Medero, M.G. 2013. Three-dimensional modelling of high speed ballasted railway tracks. Proceedings of the ICE - Transport 166(2): 113-123. doi: 10.1680/tran.9.00048.

Brown, S.F. 1996. Soil mechanics in pavement engineering. Geotechnique 46(3): 383-426.

Burrow, M.P.N., Bowness, D., and Ghataora, G.S. 2007. A comparison of railway track foundation design methods. Proceedings of the Institution of Mechanical Engineers, Part F: Journal of Rail and Rapid Transit 221(1): 1-12. doi: 10.1243/09544097jrrt58.

Chrismer, S., and Selig, E.T. 1993. Computer model for ballast maintenance planning. In 5th International Heavy Haul Railway Conference. pp. 223-227. 
Colaço, A., Costa, P.A., and Connolly, D.P. 2016. The influence of train properties on railway ground vibrations. Structure and Infrastructure Engineering 12(5): 517-534. doi: $10.1080 / 15732479.2015 .1025291$.

Cunha, J., and Correia, A.G. 2012. Evaluation of a linear elastic 3D FEM to simulate rail track response under a high-speed train. In ICTG - Advances in Transportation Geotechnics II. Edited by Miura et al. Taylor \& Francis - Balkema, London. pp. 196201.

El Kacimi, A., Woodward, P.K., Laghrouche, O., and Medero, G. 2013. Time domain 3D finite element modelling of train-induced vibration at high speed. Computers and Structures 118: 66-73. doi: 10.1016/j.compstruc.2012.07.011.

Galvín, P., Romero, A., and Domínguez, J. 2010. Fully three-dimensional analysis of highspeed train-track-soil-structure dynamic interaction. Journal of Sound and Vibration 329(24): 5147-5163. doi: 10.1016/j.jsv.2010.06.016.

Hall, L. 2003. Simulations and analyses of train-induced ground vibrations in finite element models. Soil Dynamics and Earthquake Engineering 23(5): 403-413. doi: 10.1016/S0267-7261(02)00209-9.

Heath, D.L., Shenton, M.J., Sparrow, R.W., and Waters, J.M. 1972. Design of conventional rail track foundations. Proceedings of the Institution of Civil Engineers 51: 251-267.

Inam, A., Ishikawa, T., and Miura, S. 2012. Effect of principal stress axis rotation on cyclic plastic deformation characteristics of unsaturated base course material. Soils and Foundations 52(3): 465-480. doi: http://dx.doi.org/10.1016/j.sandf.2012.05.006.

Indraratna, B., and Salim, W. 2003. Deformation and degradation mechanics of recycled ballast stabilised with geosynthetics. Soils and Foundations 430(4): 35-46.

Indraratna, B., Salim, W., Ionescu, D., and Christie, D. 2001. Stress-strain and degradation behaviour of railway ballast under static and dynamic loading, based on large-scale 
triaxial testing. In 15th International Conference on Soil Mechanics and Geotechnical Engineering, Istanbul. pp. 2093-2096.

Indraratna, B., Thakur, P.K., and Vinod, J.S. 2010. Experimental and numerical study of railway ballast behavior under cyclic loading. International Journal of Geomechanics 10(4): 136-144. doi: 10.1061//asce/gm.1943-5622.0000055.

Jeffs, T., and Tew, G.P. 1991. A review of track design procedures, Vol. 2, Sleepers and Ballast. BHP Research - Melbourne Laboratories.

Kaynia, A.M., Madshus, C., and Zackrisson, P. 2000. Ground vibration from high-speed trains: prediction and countermeasure. Journal of Geotechnical and Geoenvironmental Engineering 126(6): 531-537.

Kouroussis, G., Verlinden, O., and Conti, C. 2011. Finite-dynamic model for infinite media: corrected solution of viscous boundary efficiency. Journal of Engineering Mechanics 137(7): 509-511. doi: 10.1061/(ASCE)EM.1943-7889.0000250.

Krylov, V.V. 1994. On the theory of railway-induced ground vibrations. Journal De Physique 4(C5): 769-772.

Lackenby, J., Christie, D., Indraratna, B., and McDowell, G. 2007. Effect of confining pressure on ballast degradation and deformation under cyclic triaxial loading. Geotechnique 57(6): 527-536. doi: 10.1680/geot.2007.57.6.527.

Lekarp, F., Isacsson, U., and Dawson, A. 2000a. State of the art. I: Resilient response of unbound aggregates. Journal of transportation Engineering 126(1): 66-75. doi: doi:10.1061/(ASCE)0733-947X(2000)126:1(66).

Lekarp, F., Isacsson, U., and Dawson, A.R. 2000b. State of the art. II: Permanent strain response of unbound aggregates. Journal of transportation Engineering 126(1): 76-83. doi: doi:10.1061/(ASCE)0733-947X(2000)126:1(66). 
Li, D. 1994. Railway track granular layer thickness design based on subgrade performance under repeated loading. In Department of Civil and Environmental Engineering. University of Massachusetts, Amherst, Massachusetts, USA.

Li, D., Hyslip, J., Sussmann, T., and Chrismer, S. 2016. Railway Geotechnics. CRC Press, Tailor \& Francis Group, Broken Sound Parkway NW, USA.

Li, D., and Selig, E.T. 1994. Resilient modulus for fine-grained subgrade soils. Journal of Geotechnical Engineering 120(6): 939-957.

Li, D., and Selig, E.T. 1995. Evaluation of railway subgrade problems. Transportation Research Record 1489: 17-25.

Li, D., and Selig, E.T. 1996. Cumulative plastic deformation for fine-grained subgrade soils. Journal of Geotechnical Engineering 122(12): 1006-1013.

Li, D., and Selig, E.T. 1998a. Method for railroad track foundation design. I: Development. Journal of Geotechnical and Geoenvironmental Engineering 124(4): 316.

Li, D., and Selig, E.T. 1998b. Method for railroad track foundation design. II: Applications. Journal of Geotechnical and Geoenvironmental Engineering 124(4): 323.

Lysmer, J., and Kuhlemeyer, R.L. 1969. Finite dynamic model for infinite media. Journal of the Engineering Mechanics Division, ASCE 95(EM4): 859-877.

Madshus, C., and Kaynia, A.M. 1999. Dynamic ground interaction; a critical issue for high speed train lines on soft soil. In Geotechnical engineering for transportation infrastructure. Edited by Barends et al. Balkema, Amsterdam, Netherlands. pp. 1-8.

Madshus, C., and Kaynia, A.M. 2000. High-speed railway lines on soft ground: Dynamic behaviour at critical train speed. Journal of Sound and Vibration 231(3): 689-701.

O'Brien, J., and Rizos, D.C. 2005. A 3D BEM-FEM methodology for simulation of high speed train induced vibrations. Soil Dynamics and Earthquake Engineering 25(4): 289-301. 
Okabe, Z. 1961. Laboratory investigation of railroad ballasts. Bulletin of the Permanent Way Society of Japan 4(4): 1-19

Powrie, W., Yang, L.A., and Clayton, C.R.I. 2007. Stress changes in the ground below ballasted railway track during train passage. Proceedings of the Institution of Mechanical Engineers. Part F, Journal of rail and rapid transit 221(2): 247-261.

Raymond, G.P. 1978. Design for railroad ballast and subgrade support. Journal of the Geotechnical Engineering Division 104(1): 45-60.

Raymond, G.P., and Diyaljee, V.A. 1979. Railroad ballast sizing and grading. Journal of the Geotechnical Engineering Division, ASCE 105(GT5): 676-681.

Raymond, G.P., and Williams, D.R. 1978. Repeated Load Triaxial Tests on a Dolomite Ballast. Journal of the Geotechnical Engineering Division 104(7): 1013-1029.

Sayeed, M.A., and Shahin, M.A. 2015. Modelling of ballasted railway track under train moving loads. In 12th Australia New Zealand Conference on Geomechanics, Wellington, New Zealand, Paper No. 132. pp. 1-8.

Sayeed, M.A., and Shahin, M.A. 2016a. Investigation into Impact of Train Speed for Behavior of Ballasted Railway Track Foundations. Procedia Engineering 143: $1152-$ 1159. doi: http://dx.doi.org/10.1016/j.proeng.2016.06.131.

Sayeed, M.A., and Shahin, M.A. 2016b. Three-dimensional numerical modelling of ballasted railway track foundations for high-speed trains with special reference to critical speed. $\begin{array}{llll}\text { Transportation } & \text { Geotechnics } & \text { 6: } & \text { doi: }\end{array}$ http://dx.doi.org/10.1016/j.trgeo.2016.01.003.

Sayeed, M.A., and Shahin, M.A. 2017. Design of ballasted railway track foundations using numerical modelling: Part II-Applications. Canadian Geotechnical Journal. doi: 10.1139/cgj-2016-0634. 
Shahin, M.A. 2009. Design of ballasted railway track foundations under cyclic loading. In 2009 GeoHunan International Conference - Slope Stability, Retaining Walls, and Foundations. American Society of Civil Engineers, Changsha, Hunan, China. pp. 6873.

Shenton, M.J. 1975. Deformation of railway ballast under repeated loading conditions. In Symposium on Railroad Track Mechanics, Princton University. pp. 387-404.

Stewart, H.E. 1982. The prediction of track performance under dynamic traffic loading. In Department of Civil Engineering. University of Massachusetts, Amherst, Massachusetts, USA.

UIC. 1994. Earthworks and Trackbed Construction For Railway Lines, UIC Code 719 R, The international Union of Railways, Parish, France.

Yang, L., Powrie, W., and Priest, J.A. 2009. Dynamic stress analysis of a ballasted railway track bed during train passage. Journal of Geotechnical and Geoenvironmental Engineering 135(5): 680-689. 


\section{List of symbols}

a material parameter depends on the subgrade soil type

$b \quad$ material parameter depends on the subgrade soil type

c cohesion

$l \quad$ sleeper length

$m$ material parameter depends on the subgrade soil type

w sleeper width

$x \quad$ regression parameter depends on the ballast type

$y \quad$ regression parameter depends on the ballast type

$z \quad$ regression parameter depends on the ballast type

A area coefficient

$C_{R} \quad$ Raleigh wave velocity

$C_{S} \quad$ shear wave velocity

E dynamic modulus of elasticity

$E_{b} \quad$ ballast modulus

$E_{S} \quad$ subgrade soil modulus

$H_{b} \quad$ granular layer thickness

$H_{b i} \quad$ thickness of each sublayer of ballast

$H_{S} \quad$ subgrade layer thickness

$H_{s i} \quad$ thickness of each sublayer of the subgrade

I moment of inertia

$I_{\varepsilon} \quad$ strain influence factor

$I_{\varepsilon_{-} b} \quad$ strain influence factor with depth in the ballast layer

$I_{\varepsilon_{-} s} \quad$ strain influence factor with depth in the subgrade layer

$I_{\left(\varepsilon_{-} s\right) a}$ allowable subgrade surface strain influence factor

$I_{\rho_{-} \mathrm{s}} \quad$ subgrade deformation influence factor

$I_{\left(\rho_{-} s\right) a}$ allowable subgrade deformation influence factor

$L \quad$ length coefficient

$L_{a} \quad$ distance between axles

$L_{b} \quad$ distance between two bogies

$L_{c} \quad$ carriage length 
$N_{b} \quad$ number of load applications on the ballast layer

$N_{b i} \quad$ number of load cycles in the ballast for wheel load $P_{s i}$

$N_{b i}^{o} \quad$ equivalent load cycles corresponding to the maximum static wheel load, $P_{s}$

$N_{s} \quad$ number of load applications in the subgrade layer

$N_{s i} \quad$ number of load cycles in the subgrade for wheel loading, $P_{s i}$

$N_{s i}^{o} \quad$ equivalent number of load cycles of the maximum static wheel load, $P_{s}$

$P_{d} \quad$ design dynamic wheel load

$P_{F} \quad$ front wheel load

$P_{R} \quad$ rear wheel load

$P_{s} \quad$ maximum static wheel load

$T_{i} \quad$ total traffic tonnage of the wheel load, $P_{s i}$

$\alpha \quad$ ratio between the applied cyclic deviatoric stress and the compressive strength

$\gamma \quad$ unit weight

$v \quad$ Poisson's ratio

$\xi \quad$ damping ratio

$\phi^{\mathrm{o}} \quad$ friction angle

$\sigma_{d} \quad$ deviatoric stress

$\sigma_{d_{-} b} \quad$ applied cyclic deviatoric stress on the ballast

$\sigma_{d_{-} s}$ deviatoric stress applied to the subgrade

$\sigma_{\left(d_{-} s\right) a}$ allowable deviatoric stress at the subgrade surface

$\sigma_{s_{-} b} \quad$ static strength of ballast under a confining pressure of $50 \mathrm{kPa}$

$\sigma_{s_{-} s} \quad$ unconfined compressive strength of the subgrade soil

$\sigma_{1} \quad$ major principal stresses

$\sigma_{3} \quad$ confining pressure is a secondary factor

$\varepsilon_{p_{-} b} \quad$ cumulative plastic strain of ballast

$\varepsilon_{\left(p_{-} b\right) i}$ plastic strain at the centre of each ballast sublayer

$\varepsilon_{p_{-} s} \quad$ cumulative plastic strain of the track subgrade soil

$\varepsilon_{\left(p_{-} s\right) i}$ plastic strain at the center of each subdivided subgrade layer

$\varepsilon_{\left(p_{-} s\right) a}$ allowable plastic strain at the subgrade surface 
$\rho_{b} \quad$ contribution to track deformation by the ballast layers

$\rho_{s} \quad$ contribution to track deformation by and subgrade layer

$\rho_{t} \quad$ total cumulative plastic deformation of the track under repeated train loading

$\rho_{t a} \quad$ allowable deformation of the track for the design traffic tonnage 


\section{Figure captions}

Fig. 1. Typical ballasted railway track cross section.

Fig. 2. Progressive shear failure at the subgrade surface.

Fig. 3. Calibration of developed empirical model for ballast plastic deformation with the experimental results.

Fig. 4. Developed 3D FE numerical model of ballasted railway track.

Fig. 5. Geometry of the X-2000 HST used for the FE numerical modelling.

Fig. 6. Deviatoric stress along the rail at the surface for: (a) ballast; and (b) subgrade.

Fig. 7. Deviatoric stress along the sleeper at different depths with: (a) ballast; and (b) subgrade.

Fig. 8. Distribution of deviatoric stress with depth for the ballast layer at various: (a) ballast modulus; and (b) subgrade modulus.

Fig. 9. Distribution of deviatoric stress with depth for the subgrade layer at various: (a) ballast modulus; and (b) subgrade modulus.

Fig. 10. Effect of granular layer thickness on the distribution of deviatoric stress with depth for: (a) soft subgrade; and (b) stiff subgrade.

Fig. 11. Distribution of deviatoric stress with depth in the subgrade layer for different subgrade thicknesses.

Fig. 12. Relationship between: (a) track deflection versus wheel spacing; and (b) wheel spacing factor versus wheel spacing.

Fig. 13. Evolution of the dynamic amplification factor versus train speed under various subgrade conditions.

Fig. 14. Influence of loading amplitudes on the time history for: (a) deviatoric stress; and (b) deviatoric strain.

Fig. 15. An example of design chart for calculation of the granular layer thickness to prevent the progressive shear failure.

Fig. 16. Development of curve 'a' of Fig. 15 from Fig. 10(a).

Fig. 17. Example of distribution of strain influence factor with depth in the ballast layer. 
Fig. 18. Design charts to calculate the granular layer thickness for preventing the excessive plastic deformation. 


\section{Table captions}

Table 1. Material parameters for various types of ballast.

Table 2. Material parameters for various types of soil (modified after data from Li and Selig 1998a).

Table 3. Material properties used in the FE numerical modelling.

Table 4. Range of variable track properties used for the deviatoric stress analysis.

Table 5. Geometry and axle loads of the X-2000 HST (modified after data fromTakemiya 2003). 


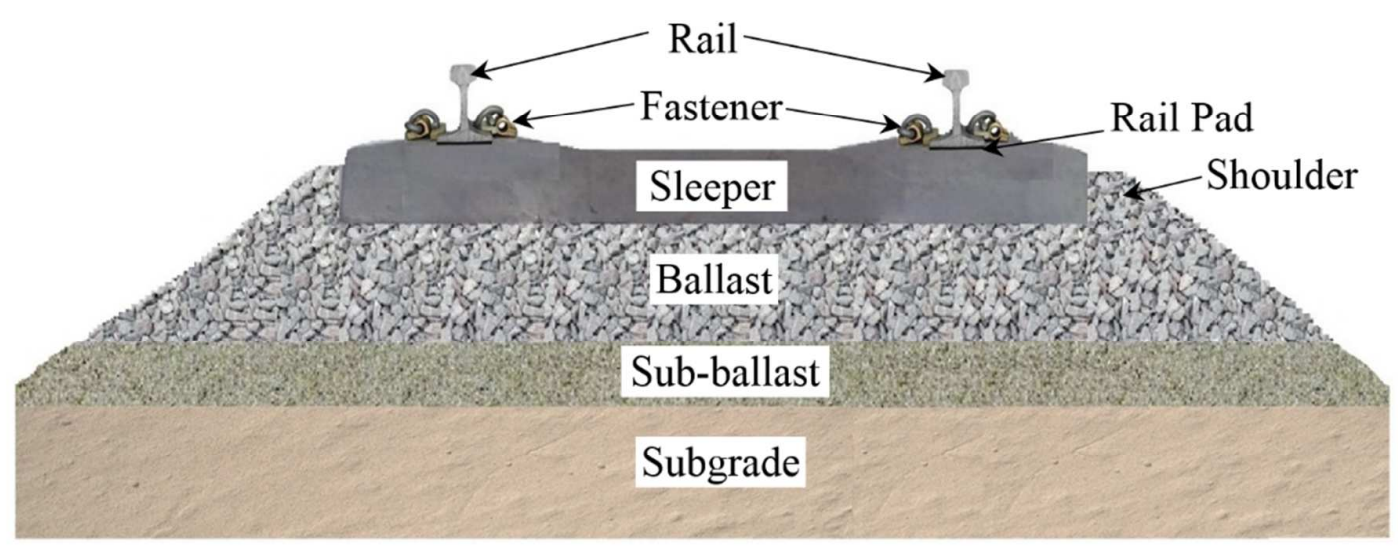

Fig. 1. Typical ballasted railway track cross section. 


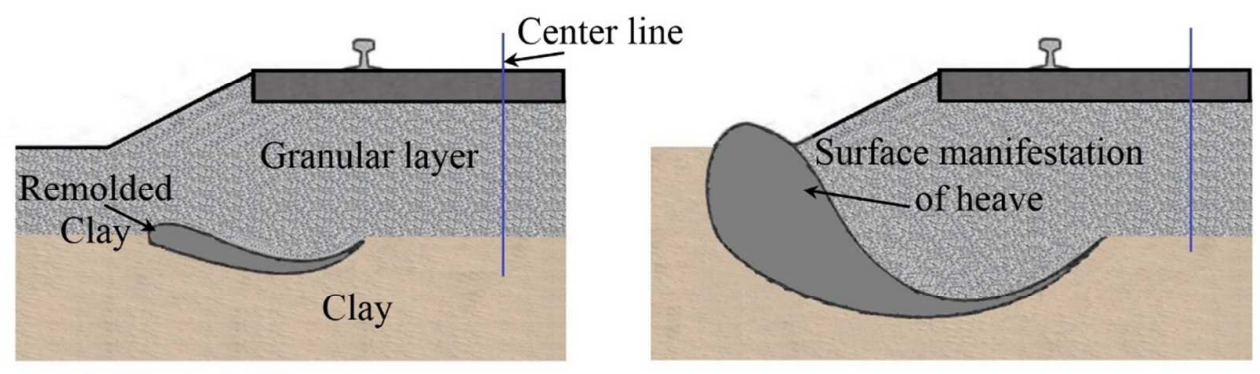

Fig. 2. Progressive shear failure at the subgrade surface. 

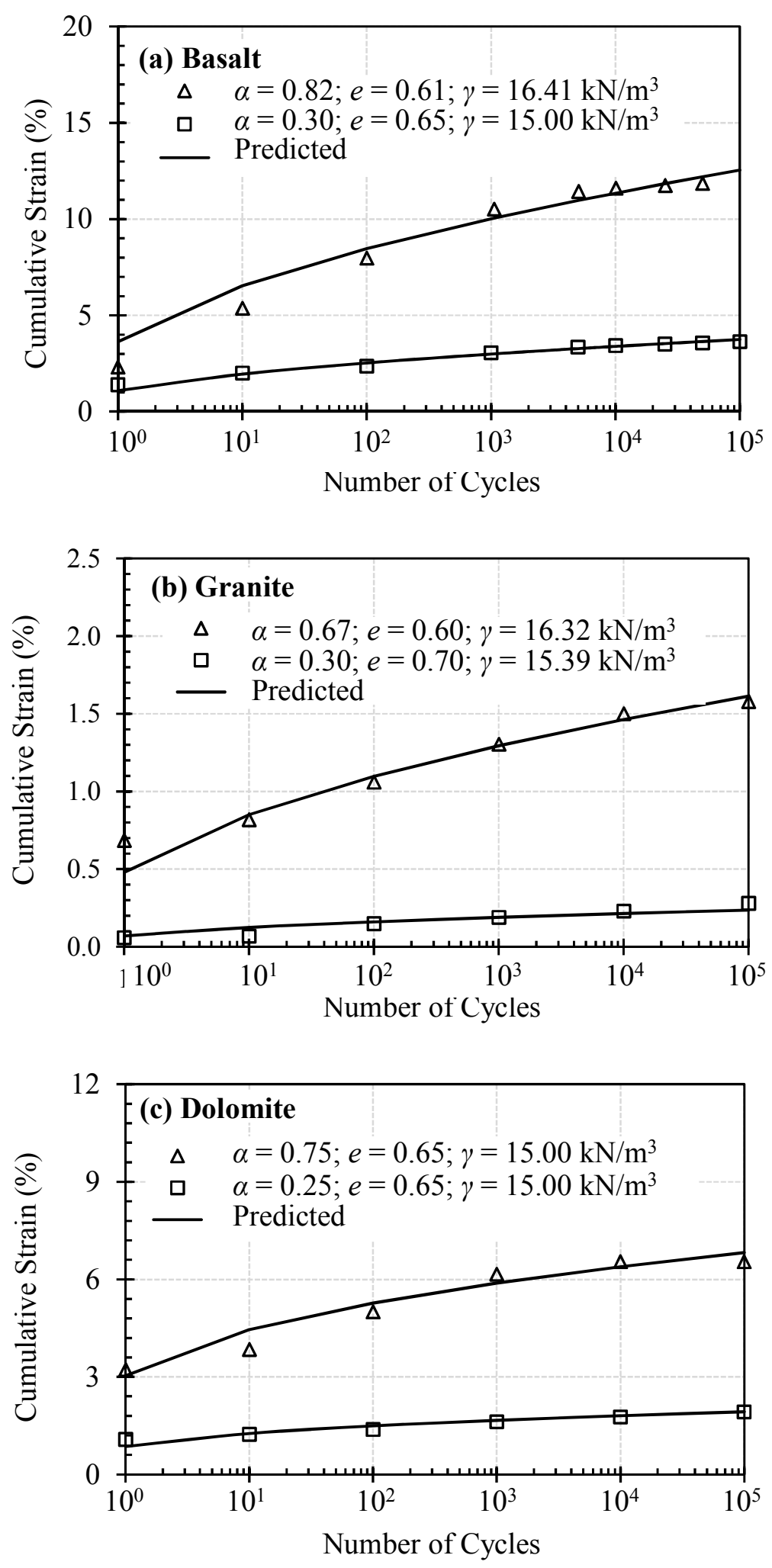

Fig. 3. Calibration of developed empirical model for ballast plastic deformation with the experimental results. 


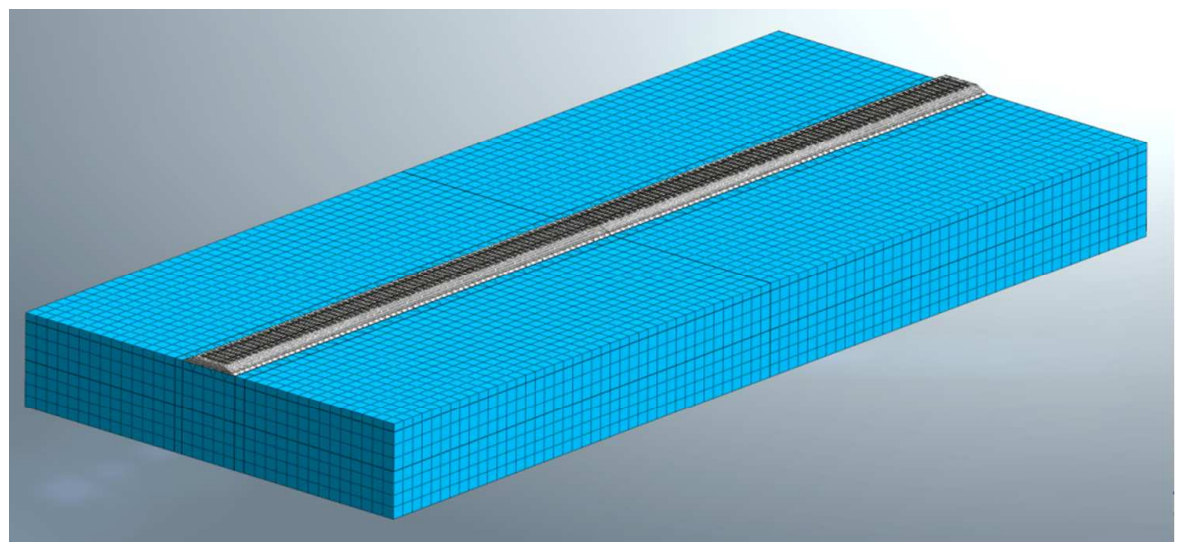

Fig. 4. Developed 3D FE numerical model of ballasted railway track. 


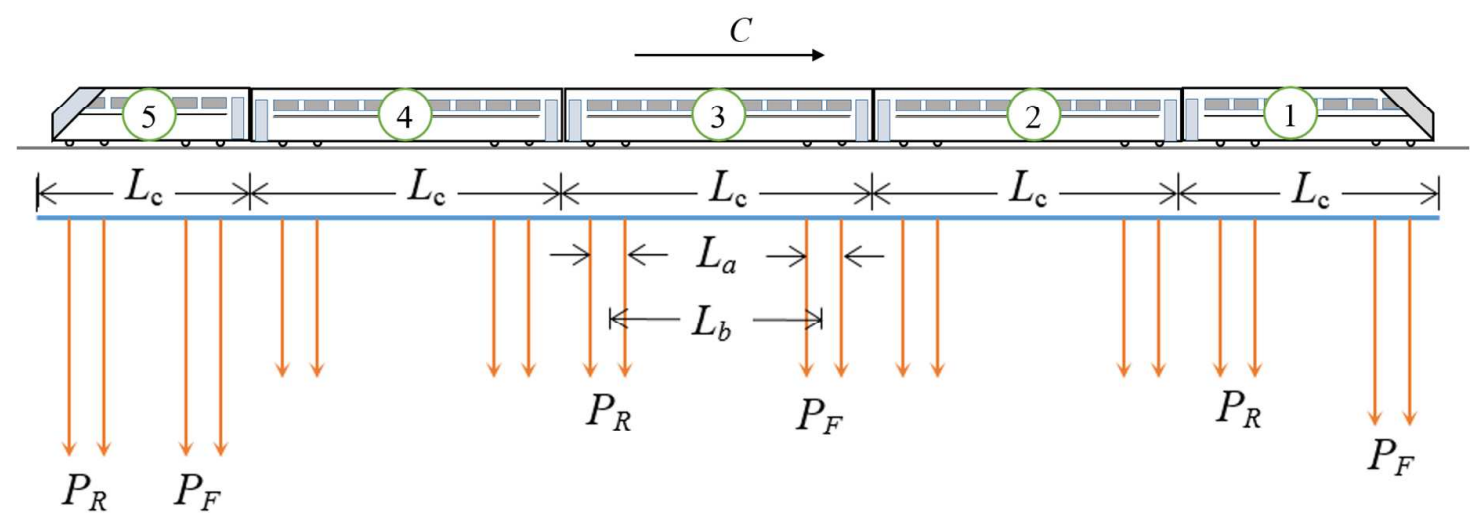

Fig. 5. Geometry of the X-2000 HST used for the FE numerical modelling. 

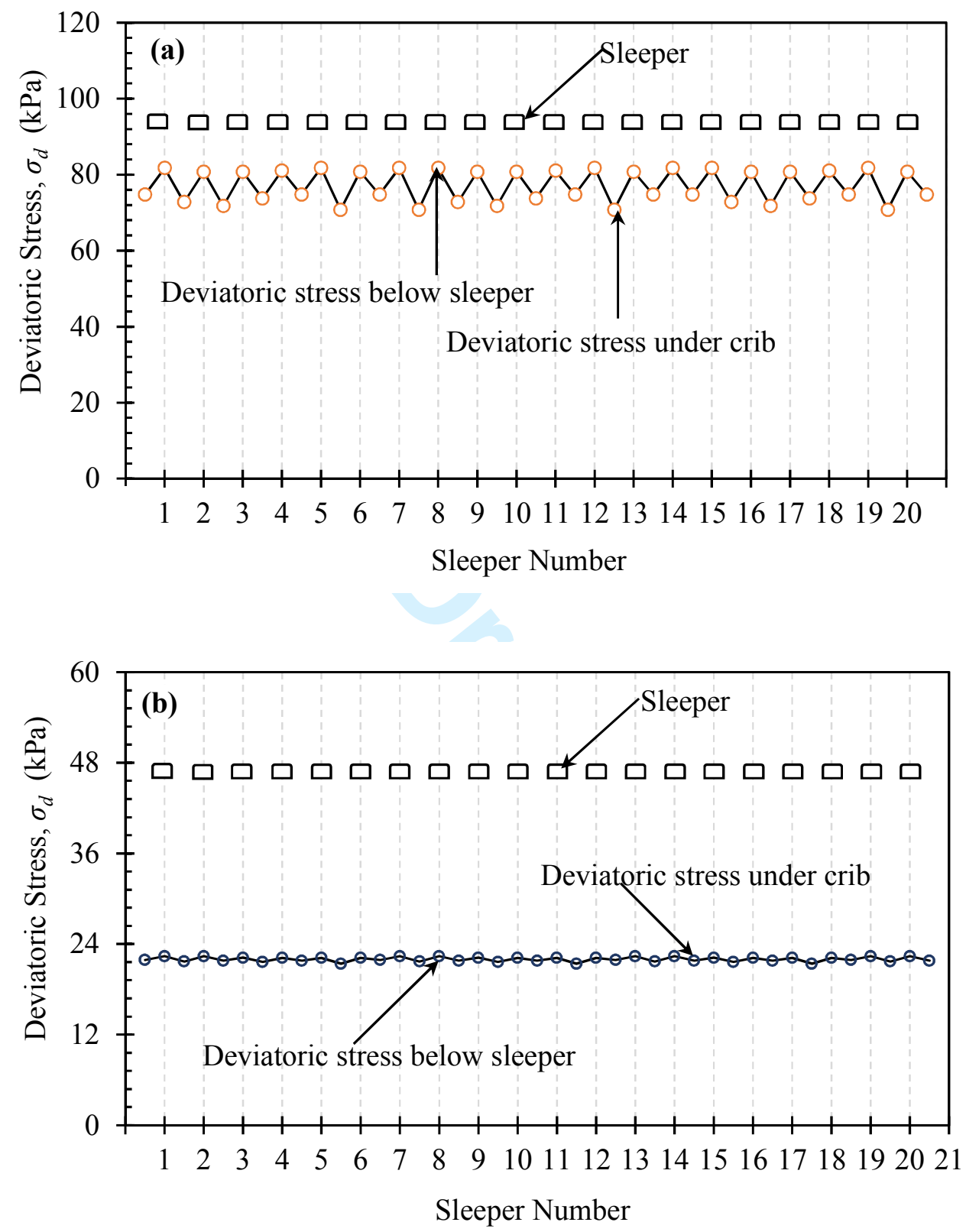

Fig. 6. Deviatoric stress along the rail at the surface for: (a) ballast; and (b) subgrade. 

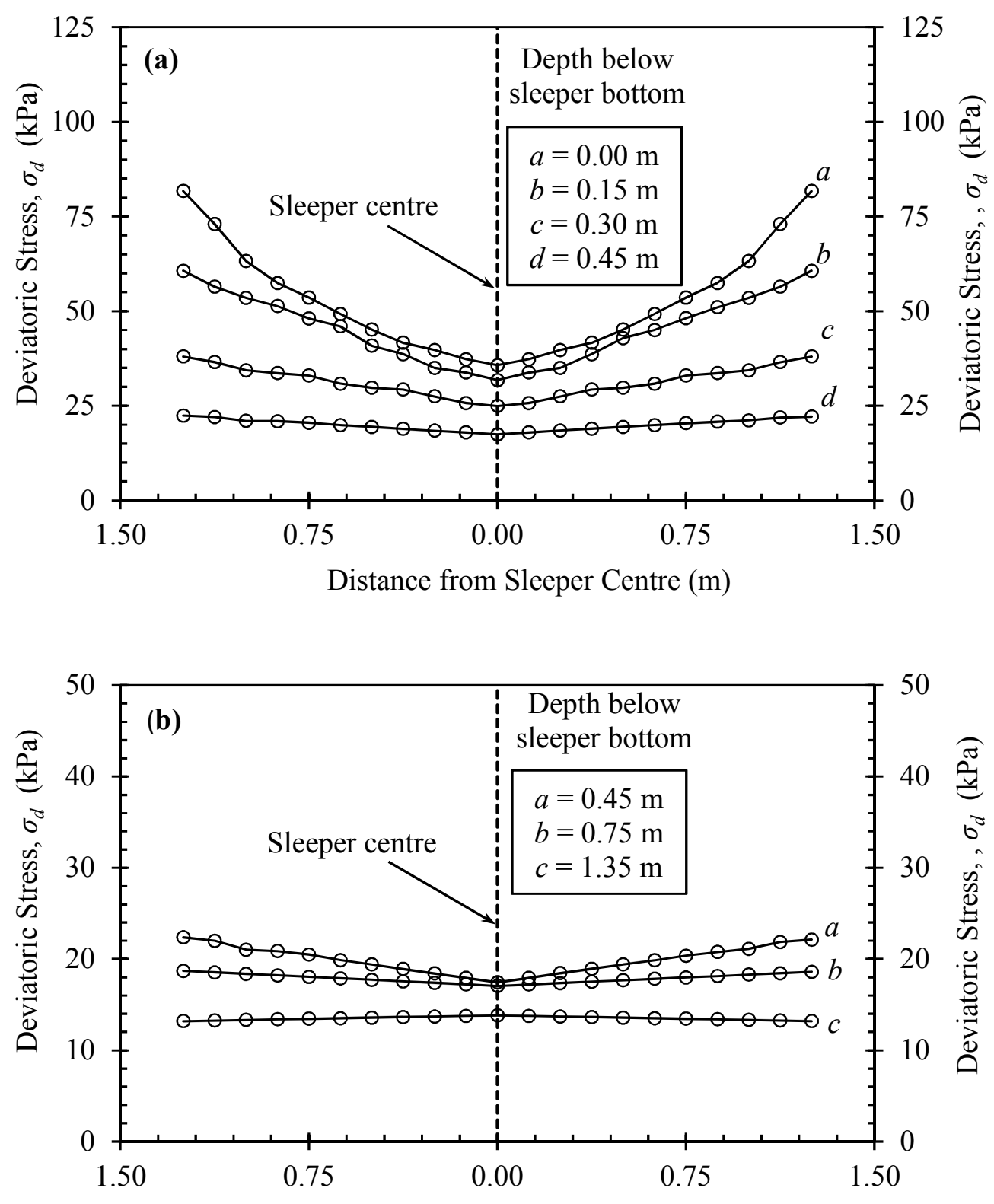

Distance from Sleeper Centre $(\mathrm{m})$

Fig. 7. Deviatoric stress along the sleeper at different depths with: (a) ballast; and (b) subgrade. 

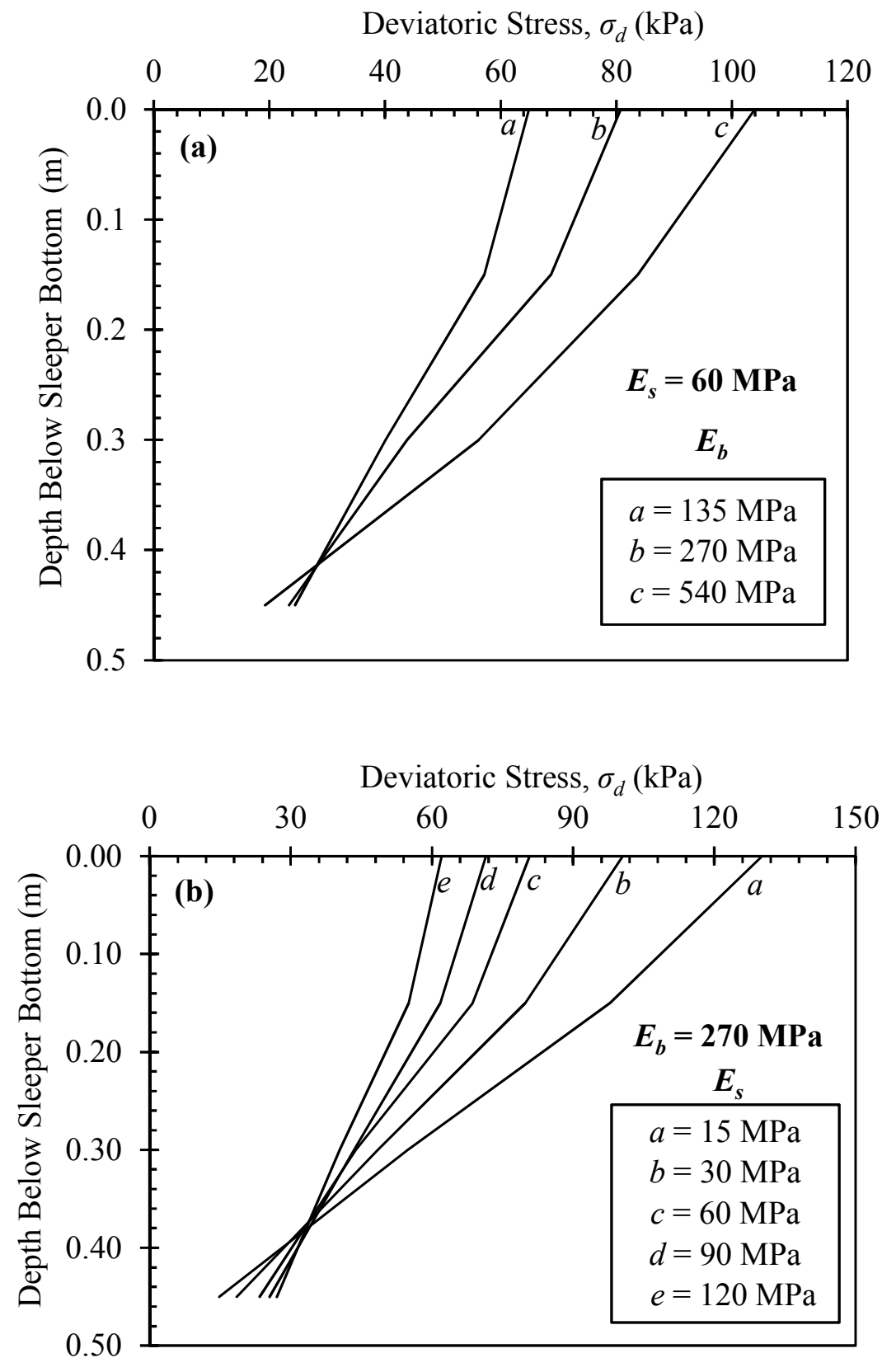

Fig. 8. Distribution of deviatoric stress with depth for the ballast layer at various: (a) ballast modulus; and (b) subgrade modulus. 

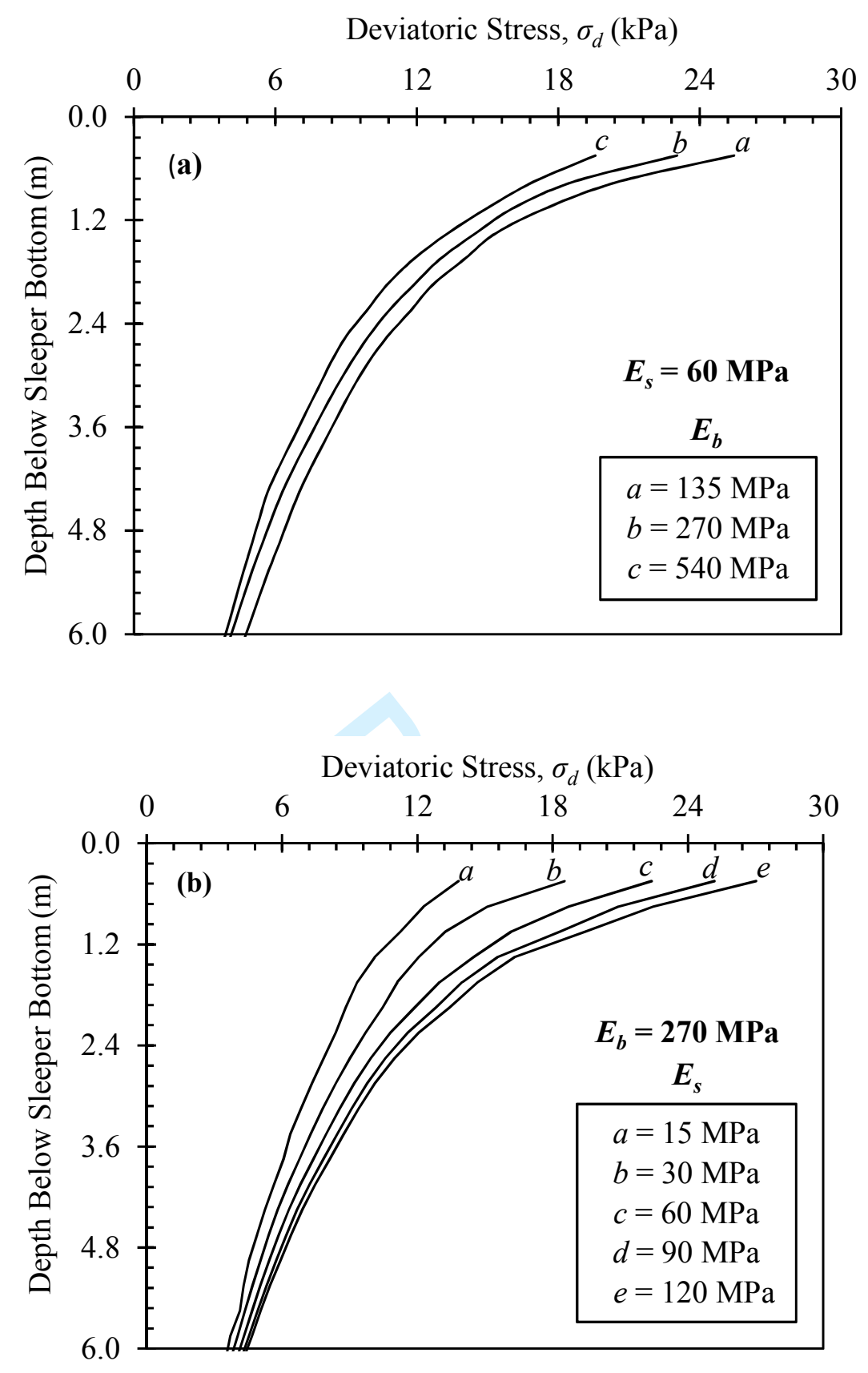

Fig. 9. Distribution of deviatoric stress with depth for the subgrade layer at various: (a) ballast modulus; and (b) subgrade modulus. 
Deviatoric Stress, $\sigma_{d}(\mathrm{kPa})$

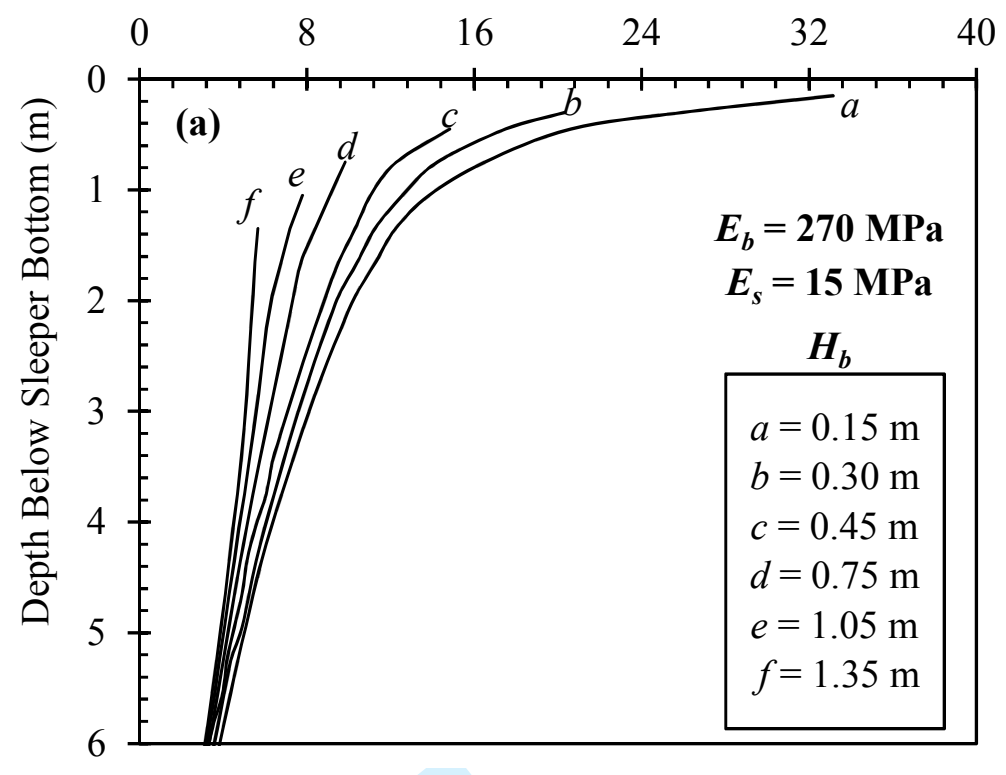

Deviatoric Stress, $\sigma_{d}(\mathrm{kPa})$

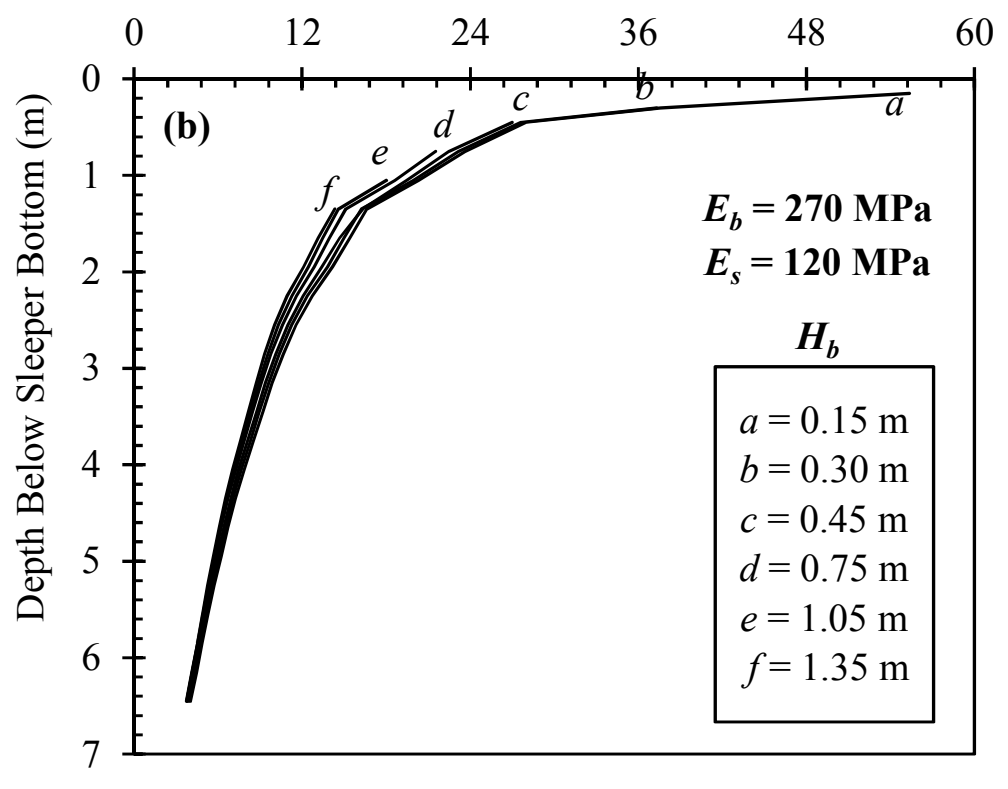

Fig. 10. Effect of granular layer thickness on the distribution of deviatoric stress with depth for:

(a) soft subgrade; and (b) stiff subgrade. 


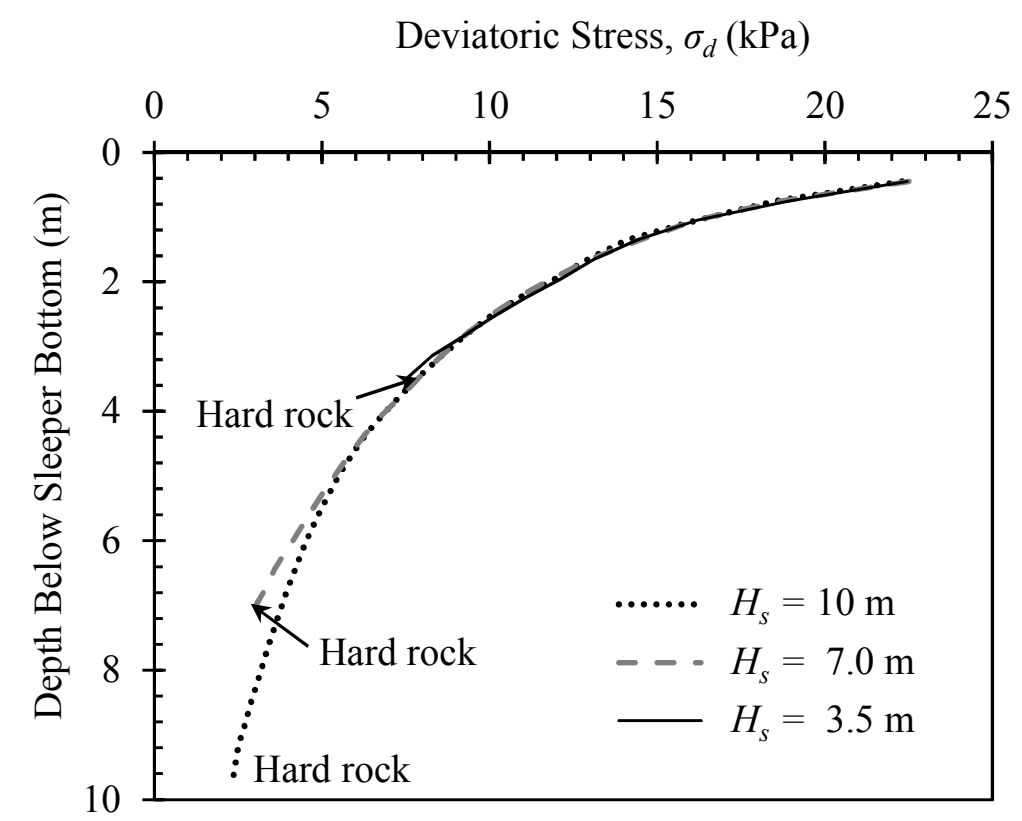

Fig. 11. Distribution of deviatoric stress with depth in the subgrade layer for different subgrade thicknesses. 

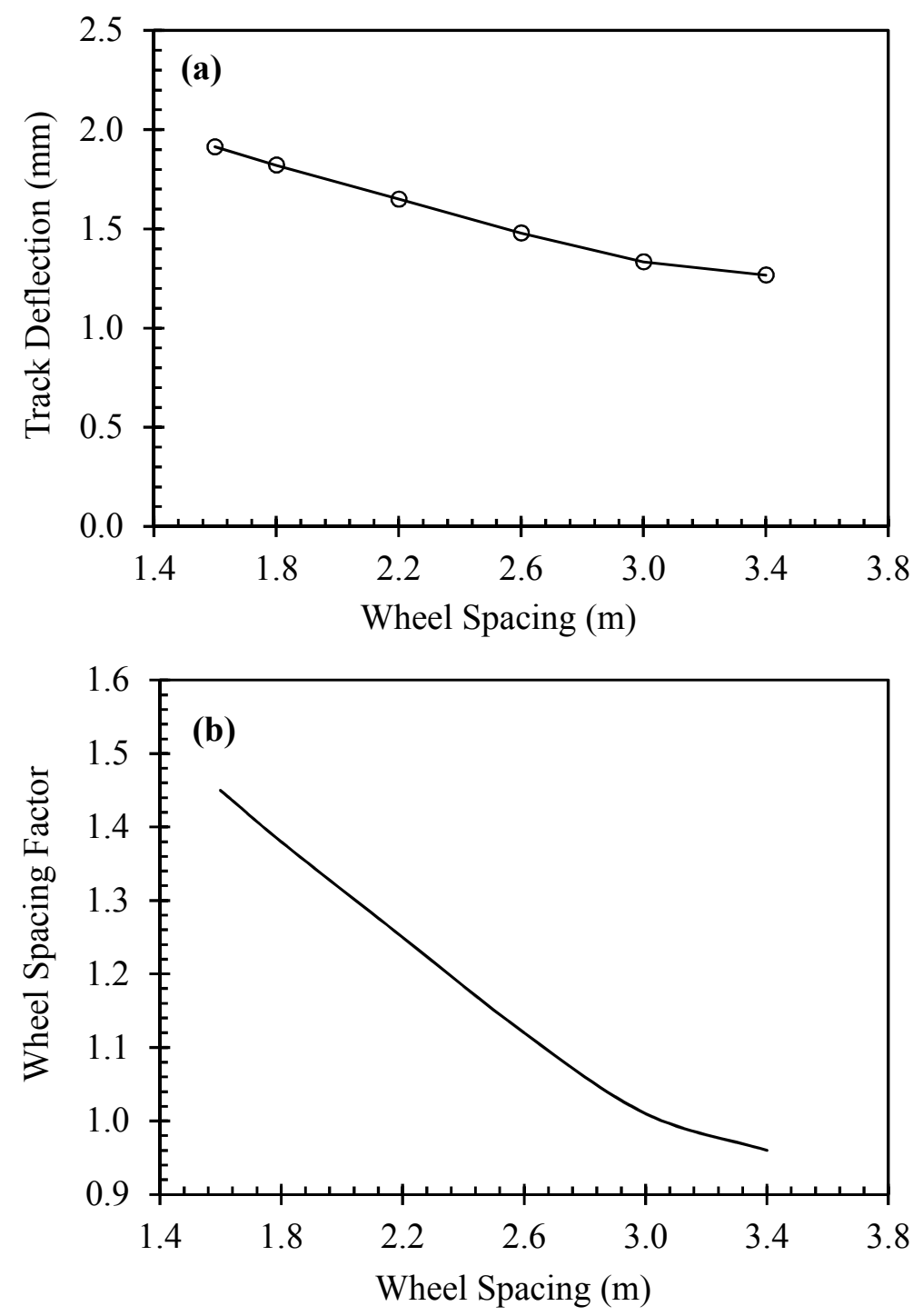

Fig. 12. Relationship between: (a) track deflection versus wheel spacing; and (b) wheel spacing factor versus wheel spacing. 

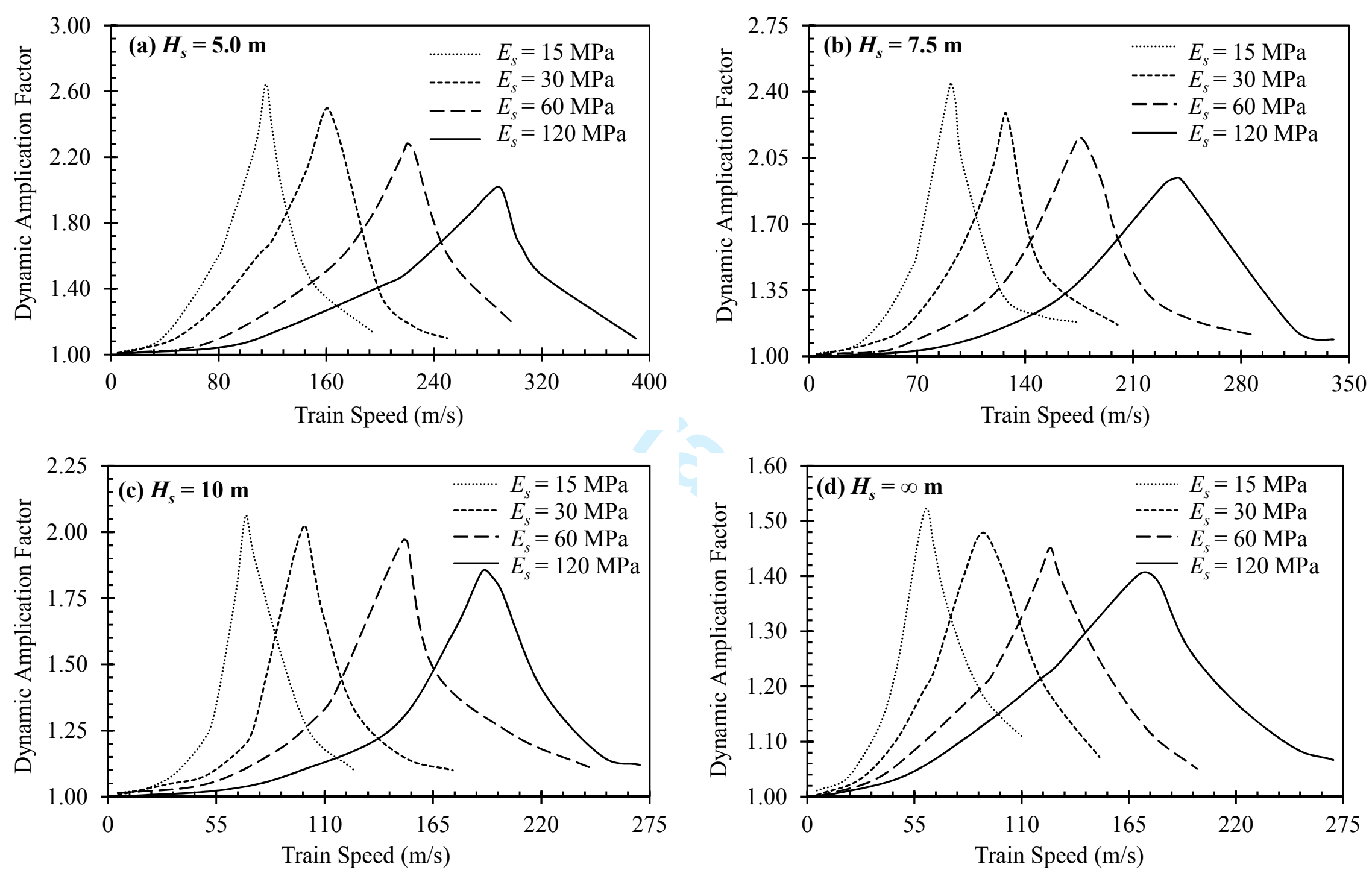

Fig. 13. Evolution of the dynamic amplification factor versus train speed under various subgrade conditions. 

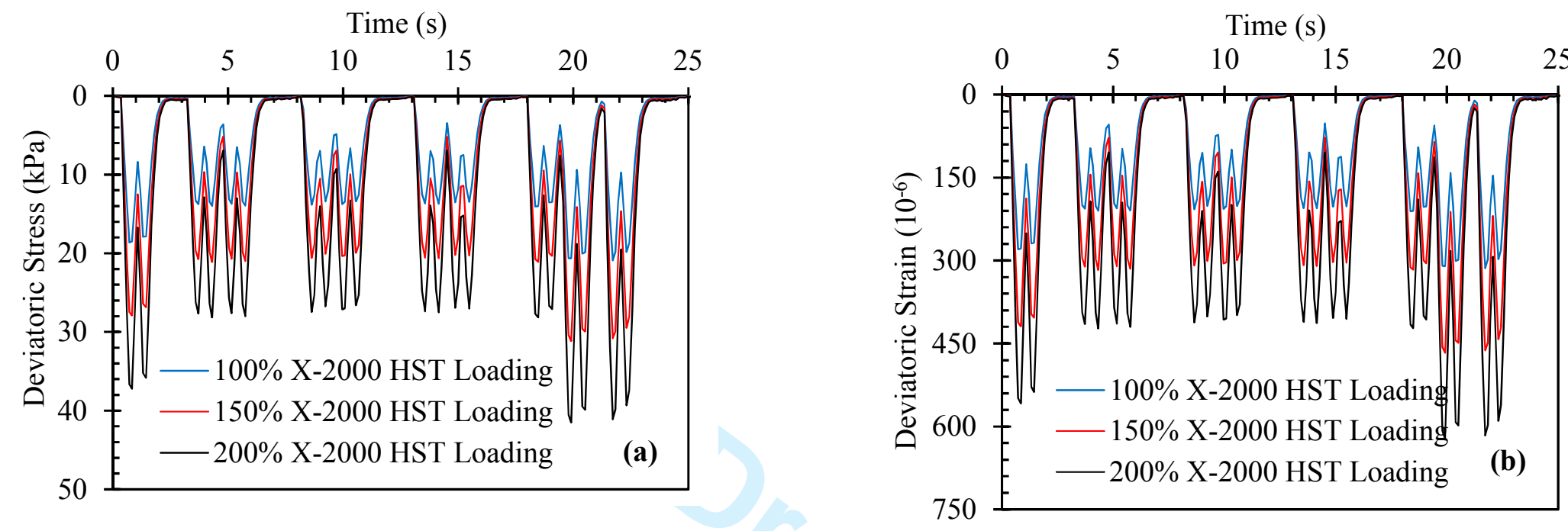

Fig. 14. Influence of loading amplitudes on the time history for: (a) deviatoric stress; and (b) deviatoric strain. 


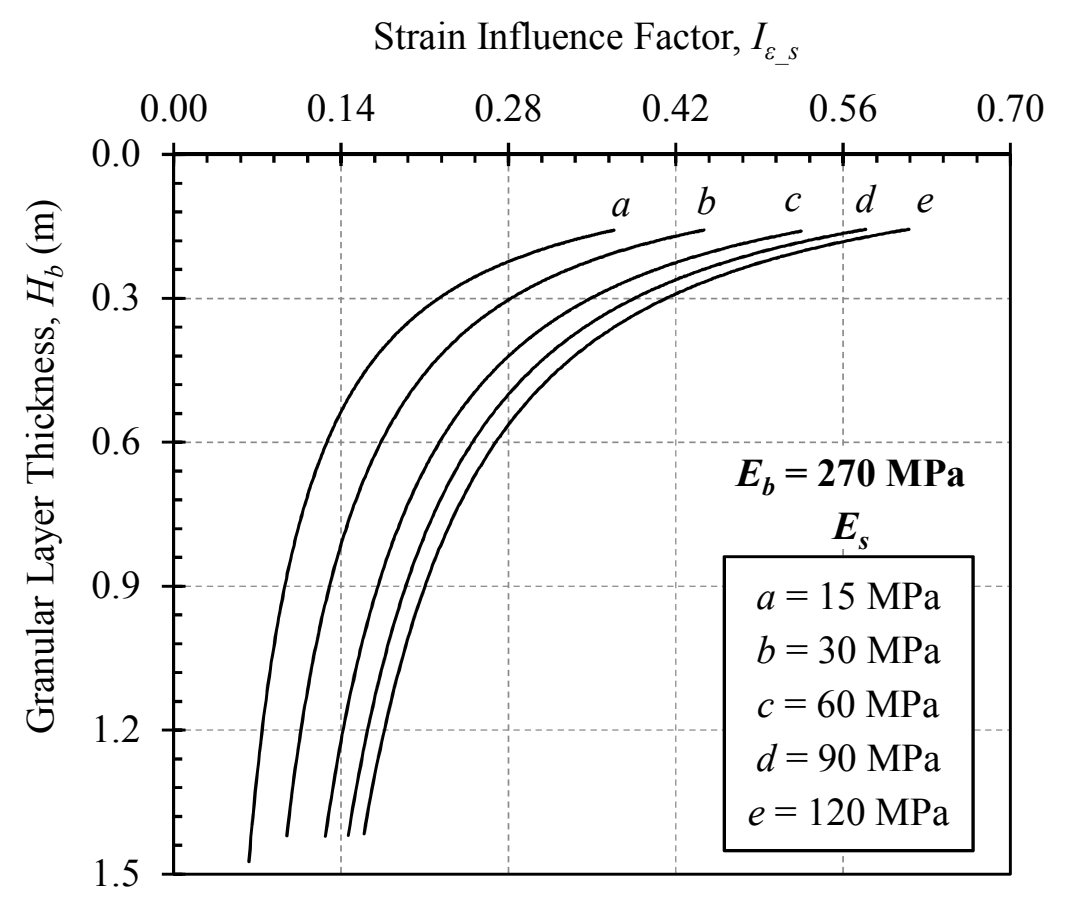

Fig. 15. An example of design chart for calculation of the granular layer thickness to prevent the progressive shear failure. 
Strain Influence Factor, $I_{\varepsilon_{-} s}$

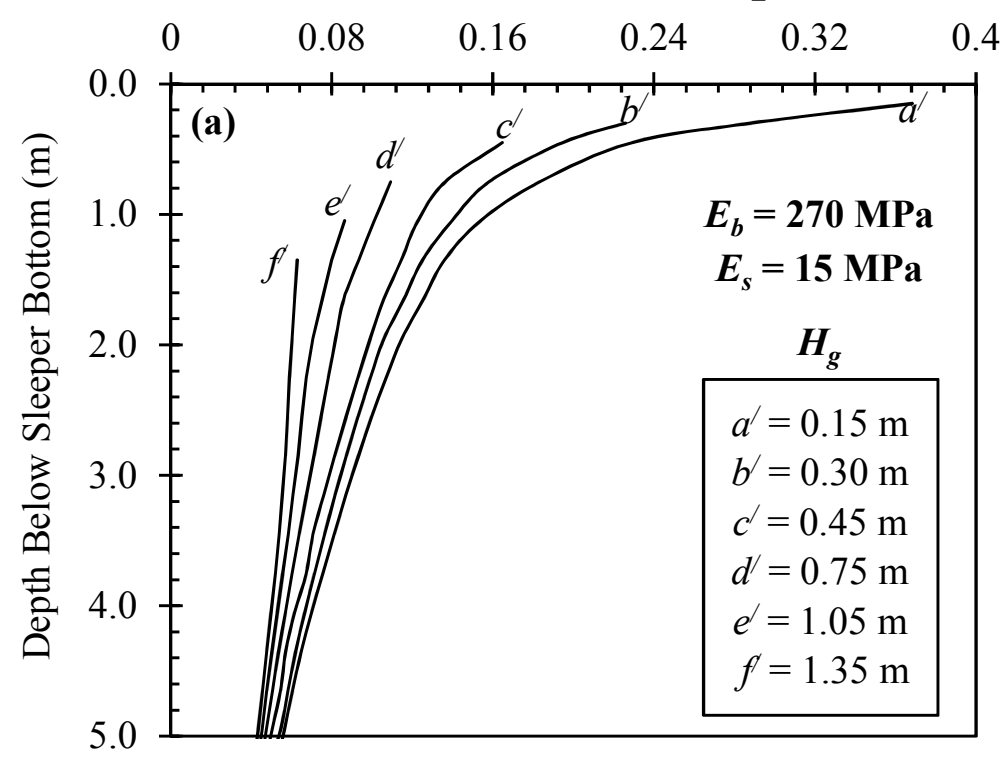

Strain Influence Factor, $I_{\varepsilon_{-} s}$

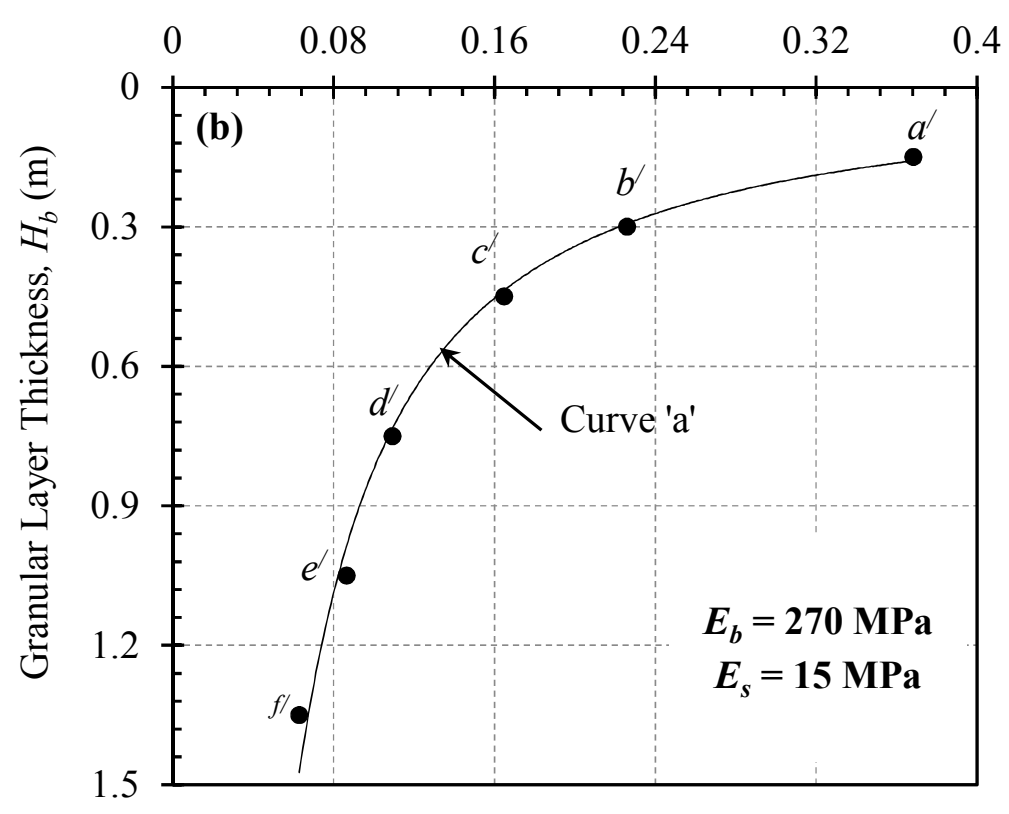

Fig. 16. Development of curve 'a' of Fig. 15 from Fig. 10a. 


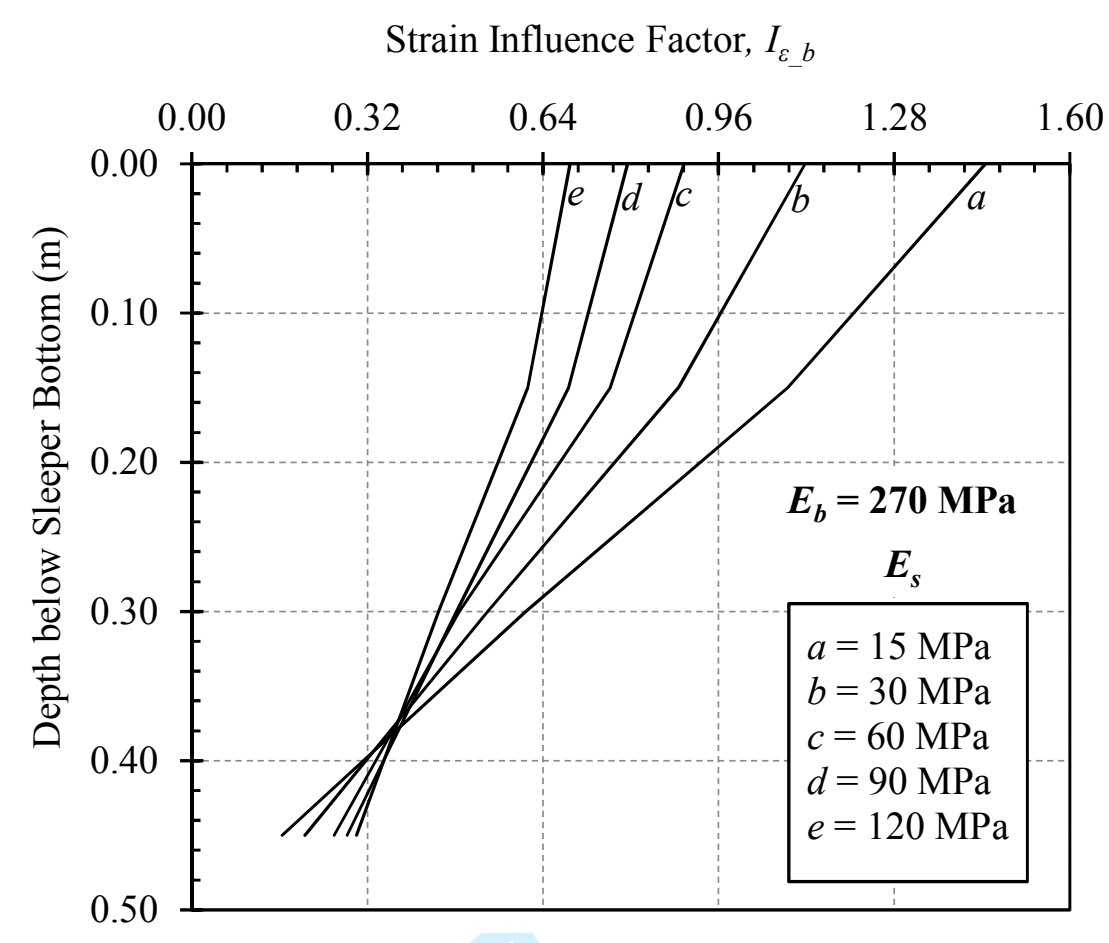

Fig. 17. Example of distribution of strain influence factor with depth in the ballast layer. 
Deformation Influence Factor, $I_{\rho_{-} s}$

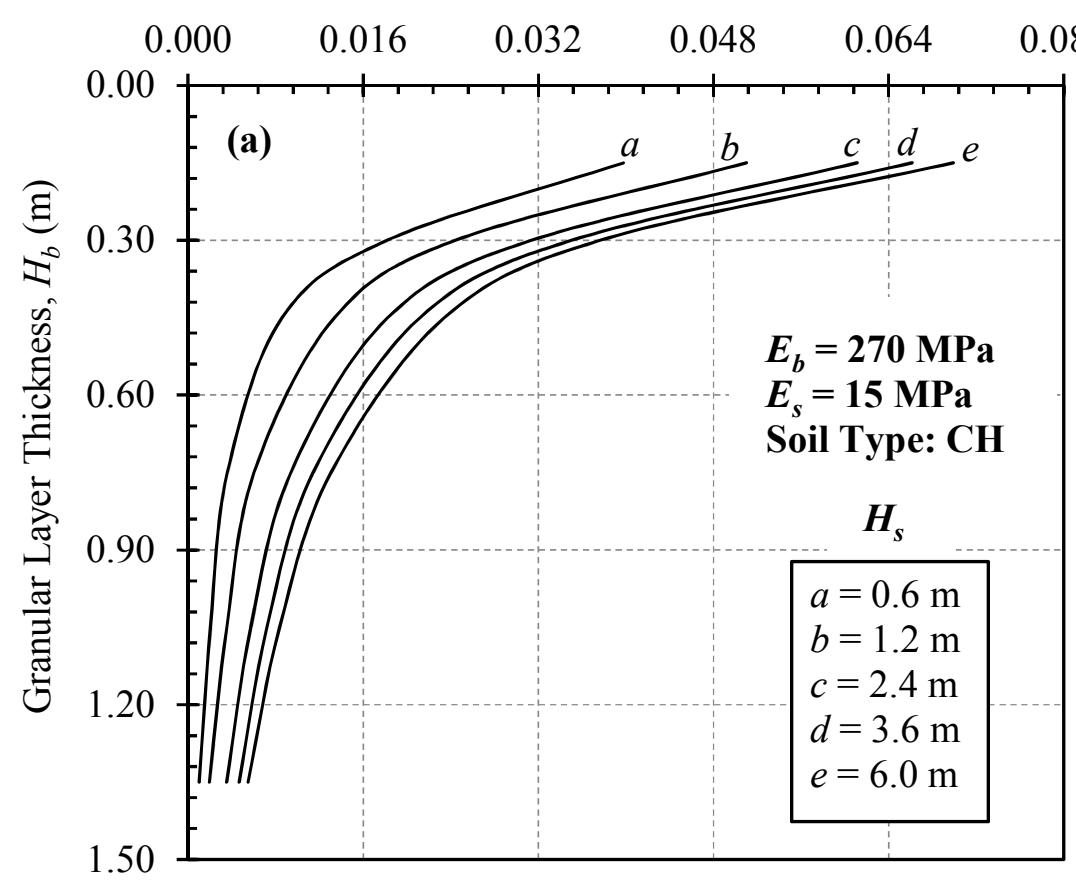

Deformation Influence Factor, $I_{\rho_{-} s}$

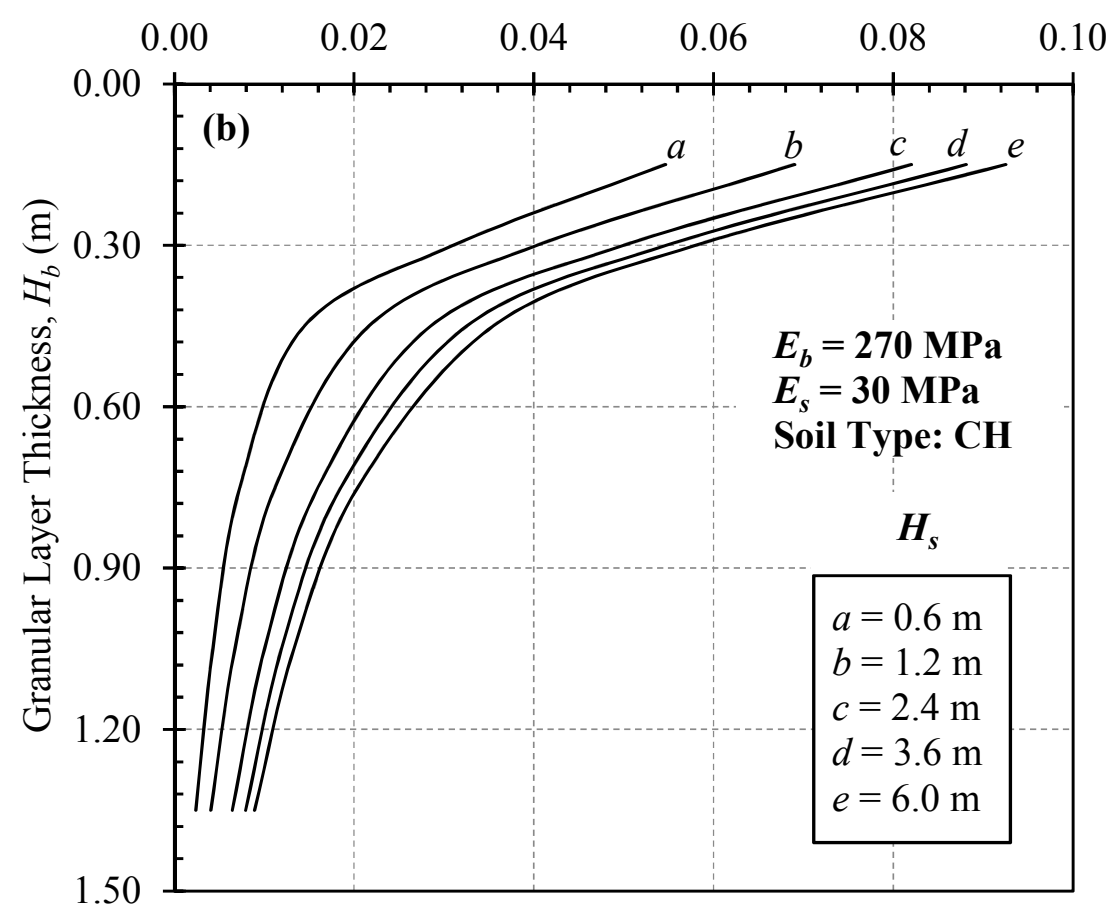

Fig. 18. Design charts to calculate the granular layer thickness for preventing the excessive plastic deformation. 
Table 1. Material parameters for various types of ballast.

\begin{tabular}{llll}
\hline Ballast type & $x$ & $y$ & $z$ \\
\hline Basalt & 4.82 & 1.42 & 0.49 \\
Granite & 1.27 & 2.41 & 0.48 \\
Dolomite & 4.23 & 1.15 & 0.32 \\
\hline
\end{tabular}


Table 2. Material parameters for various subgrade soil types (modified after data from Li and Selig 1998a).

\begin{tabular}{|c|c|c|c|c|}
\hline \multirow{2}{*}{$\begin{array}{l}\text { Material } \\
\text { parameters }\end{array}$} & \multicolumn{4}{|c|}{ Subgrade soil type } \\
\hline & $\begin{array}{l}\text { High plasticity } \\
\text { clay }(\mathrm{CH})\end{array}$ & $\begin{array}{l}\text { Low plasticity } \\
\text { clay (CL) }\end{array}$ & $\begin{array}{l}\text { High plasticity } \\
\text { silt }(\mathrm{MH})\end{array}$ & $\begin{array}{l}\text { Low plasticity } \\
\text { silt (ML) }\end{array}$ \\
\hline$a$ & 1.20 & 1.10 & 0.84 & 0.64 \\
\hline$b$ & 0.18 & 0.16 & 0.13 & 0.10 \\
\hline$m$ & 2.40 & 2.00 & 2.00 & 1.70 \\
\hline
\end{tabular}


Table 3. Material properties used in the FE numerical modelling.

\begin{tabular}{|c|c|c|}
\hline Track component & Material property & Value \\
\hline \multirow{3}{*}{ Rail } & Dynamic modulus of elasticity, $E(\mathrm{MPa})$ & 210,000 \\
\hline & Poisson's ratio, $v$ & 0.30 \\
\hline & Moment of inertia, $I\left(\mathrm{~m}^{4}\right)$ & $3.04 \times 10^{-5}$ \\
\hline \multirow{6}{*}{ Sleeper } & Dynamic modulus of elasticity, $E(\mathrm{MPa})$ & 30,000 \\
\hline & Poisson's ratio, $v$ & 0.20 \\
\hline & Unit weight, $\gamma\left(\mathrm{kN} / \mathrm{m}^{3}\right)$ & 20.2 \\
\hline & Length, $l(\mathrm{~m})$ & 2.50 \\
\hline & Width, $w(\mathrm{~m})$ & 0.27 \\
\hline & Thickness (m) & 0.20 \\
\hline \multirow{8}{*}{ Ballast } & Dynamic modulus of elasticity, $E(\mathrm{MPa})$ & 270 \\
\hline & Poissons ratio, $v$ & 0.30 \\
\hline & Unit weight, $\gamma\left(\mathrm{kN} / \mathrm{m}^{3}\right)$ & 17.3 \\
\hline & Cohesion, $c(\mathrm{kPa})$ & 0.00 \\
\hline & Friction angle, $\phi^{\circ}$ & 50.0 \\
\hline & Thickness, $H(\mathrm{~m})$ & 0.45 \\
\hline & Shear wave velocity, $C_{s}(\mathrm{~m} / \mathrm{s})$ & 243 \\
\hline & Damping ratio, $\xi$ & 0.03 \\
\hline \multirow{7}{*}{ Subgrade Soil } & Dynamic modulus of elasticity, $E(\mathrm{MPa})$ & 60.0 \\
\hline & Poissons ratio, $v$ & 0.35 \\
\hline & Unit weight, $\gamma\left(\mathrm{kN} / \mathrm{m}^{3}\right)$ & 18.8 \\
\hline & Thickness, $H(\mathrm{~m})$ & 7.50 \\
\hline & Shear wave velocity, $C_{s}(\mathrm{~m} / \mathrm{s})$ & 108 \\
\hline & Raleigh wave velocity, $C_{R}(\mathrm{~m} / \mathrm{s})$ & 101 \\
\hline & Damping ratio, $\xi$ & 0.03 \\
\hline
\end{tabular}


Table 4. Range of variable track properties used in the deviatoric stress analysis.

\begin{tabular}{llll}
\hline Parameter & Lower bound & Nominal & Upper bound \\
\hline Ballast modulus, $E_{b}(\mathrm{MPa})$ & 135 & 270 & 540 \\
Subgrade modulus, $E_{S}(\mathrm{MPa})$ & 15 & 60 & 120 \\
Ballast thickness, $H_{b}(\mathrm{~m})$ & 0.15 & 0.45 & 1.35 \\
Subgrade thickness, $H_{s}(\mathrm{~m})$ & 3.75 & 7.50 & 10.00 \\
\hline
\end{tabular}


Table 5. Geometry and axle loads of the X-2000 HST (modified after data fromTakemiya 2003).

\begin{tabular}{lllllll}
\hline \multirow{2}{*}{ Car number, $n$} & \multicolumn{2}{l}{ Spacing } & & & \multicolumn{2}{l}{ Standard wheel load } \\
\cline { 2 - 3 } \cline { 6 - 7 } & $L_{a}(\mathrm{~m})$ & $L_{b}(\mathrm{~m})$ & $L_{c}(\mathrm{~m})$ & & $P_{F}(\mathrm{kN})$ & $P_{R}(\mathrm{kN})$ \\
\hline 1 & 2.9 & 14.5 & 22.2 & & 81.0 & 61.3 \\
2 & 2.9 & 17.7 & 24.4 & & 61.3 & 61.3 \\
4 & 2.9 & 17.7 & 24.4 & & 61.3 & 61.3 \\
5 & 2.9 & 17.7 & 24.4 & & 61.3 & 61.3 \\
\hline
\end{tabular}

